\title{
THE
}

\section{Numerical Simulations and Observations of Surface Wave Fields under an Extreme Tropical Cyclone}

\author{
Yalin Fan \\ University of Rhode Island \\ Isaac Ginis \\ University of Rhode Island, iginis@uri.edu \\ Tetsu Hara \\ University of Rhode Island, thara@uri.edu \\ C. Wayne Wright
}

Edward J. Walsh

Follow this and additional works at: https://digitalcommons.uri.edu/gsofacpubs

\section{Citation/Publisher Attribution}

Fan, Y., Ginis, I., Hara, T., Wright, C. W., \& Walsh, E. J. (2009). Numerical Simulations and Observations of Surface Wave Fields under an Extreme Tropical Cyclone. Journal of Physical Oceanography, 39, 2097-2116. doi: 10.1175/2009JP04224.1

Available at: https://doi.org/10.1175/2009JP04224.1

This Article is brought to you for free and open access by the Graduate School of Oceanography at DigitalCommons@URI. It has been accepted for inclusion in Graduate School of Oceanography Faculty Publications by an authorized administrator of DigitalCommons@URI. For more information, please contact digitalcommons-group@uri.edu. 


\title{
Numerical Simulations and Observations of Surface Wave Fields under an Extreme Tropical Cyclone
}

\author{
YALIN FAN, ISAAC GINIS, AND TETSU HARA \\ Graduate School of Oceanography, University of Rhode Island, Narragansett, Rhode Island \\ C. WAYNE WRIGHT* AND EDWARD J. WALSH ${ }^{+}$ \\ NASA Goddard Space Flight Center, Wallops Island, Virginia
}

(Manuscript received 21 January 2009, in final form 25 March 2009)

\begin{abstract}
The performance of the wave model WAVEWATCH III under a very strong, category 5 , tropical cyclone wind forcing is investigated with different drag coefficient parameterizations and ocean current inputs. The model results are compared with field observations of the surface wave spectra from an airborne scanning radar altimeter, National Data Buoy Center (NDBC) time series, and satellite altimeter measurements in Hurricane Ivan (2004). The results suggest that the model with the original drag coefficient parameterization tends to overestimate the significant wave height and the dominant wavelength and produces a wave spectrum with narrower directional spreading. When an improved drag parameterization is introduced and the wavecurrent interaction is included, the model yields an improved forecast of significant wave height, but underestimates the dominant wavelength. When the hurricane moves over a preexisting mesoscale ocean feature, such as the Loop Current in the Gulf of Mexico or a warm- and cold-core ring, the current associated with the feature can accelerate or decelerate the wave propagation and significantly modulate the wave spectrum.
\end{abstract}

\section{Introduction}

Tropical cyclone-generated wave fields are of interest both scientifically for understanding wind-wave interaction physics and operationally for predicting potentially hazardous conditions for ship navigation and coastal regions. There have been considerable efforts made to understand the characteristics of tropical cyclonegenerated surface waves through both measurements and numerical modeling. Wright et al. (2001) and Walsh et al. (2002) studied the spatial variation of hurricane directional wave spectra for both open ocean and landfall cases using the National Aeronautics and Space Admin-

\footnotetext{
* Current affiliation: U.S. Geological Survey, Florida Integrated Science Center, St. Petersburg, Florida.

+ Current affiliation: NOAA/Earth System Research Laboratory, Boulder, Colorado.
}

Corresponding author address: Yalin Fan, Graduate School of Oceanography, University of Rhode Island, Narragansett, RI 02882.

E-mail: yalin@gso.uri.edu istration (NASA) Airborne Scanning Radar Altimeter (SRA). These measurements have provided detailed wave characteristics at a specific place and time. Moon et al. (2003) conducted a detailed comparison between WAVEWATCH III (WW3) wave model simulations and observations of the spatial distribution of hurricane directional wave spectra obtained from NASA SRA in Hurricane Bonnie (1998), a category 2-3 tropical cyclone on the Saffir-Simpson hurricane intensity scale (SSHS). Excluding shallow areas near the shore, the model results yielded good agreement with observations of directional spectrum as well as significant wave height, dominant wavelength, and dominant wave direction (wavelength and direction at the peak frequency of the wave spectrum). Later studies of Chao et al. (2005), Tolman and Alves (2005), and Tolman et al. (2005) found that WW3 overestimates the significant wave height under very high wind conditions in strong hurricanes. Moon et al. (2008) suggested that one of the reasons for the overestimation of the significant wave height is overestimation of the drag coefficient used in WW3 at very high winds. Comparing with buoy wave measurements during Hurricane Katrina in 2005 (SSHS 
category 5 in the Gulf of Mexico), they found that WW3 simulations with a reduced drag coefficient yielded more accurate simulations.

During Hurricane Ivan (SSHS category 4-5 in the Caribbean Sea and Gulf of Mexico) in 2004, three sets of detailed SRA wave spectra measurements were collected by NASA through a joint effort between the NASA Goddard Space Flight Center and National Oceanic and Atmospheric Administration (NOAA)/ Atlantic Oceanographic and Meteorological Laboratory/ Hurricane Research Division (HRD). These observations, together with satellite measurements and National Data Buoy Center (NDBC) buoy time series, are used in this study to evaluate the WW3 predictions in extreme tropical cyclones. In particular, we investigate if an improved drag coefficient parameterization and inclusion of the effect of wave-current interaction may improve the wave predictions using WW3.

The outline of this paper is as follows: the wave and ocean models are described in section 2 . The available observations are presented in section 3 . Section 4 provides a new method for wind field specification. The results are presented and discussed in section 5. A summary and conclusions are given in section 6 .

\section{Methodology}

\section{a. The wave model}

The ocean surface wave model, WAVEWATCH III (Tolman 1998), has been used operationally at NOAA/ National Centers for Environmental Prediction (NCEP) for more than a decade. The model was validated over a global-scale wave forecast and a regional wave forecast (Tolman 1998, 2002; Tolman et al. 2002; Wingeart et al. 2001). WAVEWATCH III explicitly accounts for wind input, wave-wave interaction, and dissipation due to whitecapping and wave-bottom interaction, and solves the spectral action density balance equation for directional wavenumber spectra. The wave spectrum of the model is discretized using 24 directions and 40 intrinsic (relative) frequencies extending from 0.0285 to $1.1726 \mathrm{~Hz}$, with a logarithmic increment of $f_{n+1}=1.1 f_{n}$, where $f_{n}$ is the $n$th frequency. The intrinsic frequency is related to the wavenumber (magnitude) $k$ through the dispersion relation. The model domain is set to $5^{\circ}-32^{\circ} \mathrm{N}$ in the latitudinal direction and $95^{\circ}-48^{\circ} \mathrm{W}$ in the longitudinal direction, with a grid increment of $1 / 12^{\circ}$ in both directions for all experiments.

Moon et al. (2004a,b) have shown that the drag coefficient used in WW3 is significantly larger than estimates based on a coupled wave-wind model (CWW) that explicitly integrates the waveform drag. The CWW results are more consistent with recent field and laboratory observations of the drag coefficient (Powell et al. 2003; Donelan et al. 2004; Black et al. 2007). Moon et al. (2008) found that using the CWW model in WW3 yielded improved wave predictions during Hurricane Katrina (2005).

In this study, we have conducted three sets of experiments with the WW3 model. In experiment A, the original drag coefficient parameterization in WW3 is used to force the wave model. In experiment B, the original drag coefficient parameterization has been replaced by the CWW model in calculating the wind input term in WW3. In the CWW model, WW3 is used to estimate the wave spectra near the peak. The spectra in the high-frequency range (equilibrium range) beyond the model resolution are parameterized by the analytical model of Hara and Belcher (2002). The resulting spectrum is then incorporated into the wave boundary layer model of Hara and Belcher (2004) to explicitly calculate the wave-induced stress vector, the mean wind profile, and the drag coefficient. The CWW model treats the wind stress as a vector quantity to consider the influence of dominant waves that propagate at a large angle to the local wind. It thus makes possible the estimation of the wind stress for any given surface wave field, even for the complex seas encountered under tropical cyclones.

In experiment $C$, we use the same setup for the wave model as in experiment $\mathrm{B}$, but also introduce ocean currents that are produced by the ocean model described below in response to hurricane forcing. Funakoshi et al. (2008) also used a similar approach to study storm tides in the St. Johns River under Hurricane Floyd (1999). There are two significant ways the ocean current $\left(\mathbf{U}_{c}\right)$ impacts the wave field in the WW3 model. First, through the wind input term in the calculation of the wind stress. When ocean current is present, the $10-\mathrm{m}$ wind velocity input $\left(\mathbf{U}_{10}\right)$ is replaced by the relative wind velocity $\mathbf{U}_{10}-\mathbf{U}_{c}$. Second, the wave action equation, which is solved in WW3, accounts for the modulation by the ocean current such that

$$
\begin{aligned}
\frac{\partial N}{\partial t}+\nabla_{x} \cdot\left[\left(\mathbf{U}_{c}+\mathbf{C}_{g}\right) N\right]-\frac{\partial}{\partial k}\left(\mathbf{k} \cdot \frac{\partial \mathbf{U}_{c}}{\partial s} N\right) \\
+\frac{\partial}{\partial \theta}\left(\frac{1}{k} \mathbf{k} \cdot \frac{\partial \mathbf{U}_{c}}{\partial m} N\right)=F,
\end{aligned}
$$

where $N=\psi / \omega$ is the wave action spectrum, $\mathbf{C}_{g}$ is group velocity vector, $\mathbf{k}$ is the wavenumber vector, $\theta$ is the wave direction, $s$ is a coordinate in the wave direction, $m$ is the coordinate perpendicular to $s, F$ represents all forcing terms, and $\mathbf{U}_{c}$ is the ocean current at the depth of $L /(4 \pi)$ ( $L$ is the mean wavelength), which modifies the apparent phase speed of the wave train [please refer to Fan et al. (2009a) for detailed explanation]. The 
variable ocean current not only modifies the speed of the wave action flux [second term of Eq. (1)] but also modifies the wavenumber of a particular wave packet as it propagates [third and fourth terms of Eq. (1)].

\section{b. The ocean model}

In this study, the ocean currents are calculated using the Princeton Ocean Model (POM). POM is a threedimensional, primitive equation model with complete thermohaline dynamics, sigma vertical coordinate system, and a free surface (Blumberg and Mellor 1987). We employed the version of POM used operationally in the Geophysical Fluid Dynamics Laboratory (GFDL)/ University of Rhode Island (URI) hurricane prediction system (Bender et al. 2007).

A realistic initialization of the $3 \mathrm{D}$ density and velocity fields in the ocean model is critical for proper simulation of the ocean response to a hurricane (Ginis 2002). The initialization method implemented in the GFDL/URI system is described in detail in Falkovich et al. (2005) and Yablonsky and Ginis (2008) and includes a realistic representation of the Loop Current (LC) and warm- and cold-core eddies in the Gulf of Mexico. In this method, the initial condition is first generated using the Generalized Digital Environmental Model (GDEM) monthly ocean temperature and salinity climatology (Teague et al. 1990), which has $14^{\circ}$ horizontal grid spacing and 33 vertical $z$ levels at depths ranging from 0 to $5500 \mathrm{~m}$. Then, a feature-based modeling procedure (Yablonsky and Ginis 2008) is conducted to incorporate sea surface height anomaly (SSHA) observations. Positive SSHA features (also referred to as warm features) are regions where warm upper-ocean layer (warm ocean layer is often defined as from the surface down to the depth of the $26^{\circ} \mathrm{C}$ isotherm) (Shay et al. 2000) is deeper than climatology. On the other hand, negative SSHA features are regions where the warm upper-ocean layer is shallower than climatology. These positive and negative SSHA features are frequently associated with warmand cold-core mesoscale eddies, respectively. In the feature-based procedure, multiple points along the LC path are specified, allowing the LC shape to be adjusted to match the observed shape derived from satellite altimetry. Then, the warm- and cold-core eddies in the Gulf of Mexico are incorporated by assuming they are elliptical in shape, with major and minor axes defined based on the SSHA data. For this study, we utilize the altimetry data from the Colorado Center for Astrodynamics Research (CCAR) Real-Time Altimetry Project through their Web site (http://argo.colorado.edu/ $\sim$ realtime/welcome/). The CCAR altimetry map on 12 September 2004 (shown in Fig. 15a) is used to ini- tialize the position and structure of the LC and a warmcore ring in the Gulf of Mexico (Fig. 15b).

\section{Wave observations during Hurricane Ivan}

Hurricane Ivan in 2004 was a classical, long-lived Cape Verde hurricane that reached SSHS category 5 strength three times. The hurricane track from 1200 UTC 8 September to 1200 UTC 16 September is shown in Fig. 1. Three sets of detailed SRA wave spectra measurements were collected by NASA through a joint effort between the NASA Goddard Space Flight Center and NOAA/HRD. The flight tracks of the NOAA aircraft carrying the SRA are shown in Fig. 1. Two sets of measurements were collected from 1615 to 2010 UTC 9 September and from 1040 to 1540 UTC 12 September when Ivan was crossing the Caribbean Sea and at its maximum intensity of category 5 . The third set of measurements was done from 2030 UTC 14 September to 0330 UTC 15 September when Ivan entered the Gulf of Mexico.

The SRA measurements covered the region within about $2^{\circ}$ of the hurricane eye. The SRA scanned a radar beam across the aircraft ground track to measure the elevation at 64 points on the sea surface. Sea surface topographic maps were produced from groups of SRA cross-track scan lines. The topography was then interpolated to a north- and east-oriented $256 \times 256$ rectangular grid of $7-\mathrm{m}$ spacing centered on the data. The elevations in the uniform grid were transformed by a two-dimensional fast Fourier transform (FFT) with wavenumber spectral resolution of $0.0035 \mathrm{rad} \mathrm{m}^{-1}$. The encounter wave spectra were Doppler corrected and the $180^{\circ}$ ambiguous spectral lobes were deleted. Wright et al. (2001) and Walsh et al. (2002) describe the process in detail.

Two satellites, Envisat-1 and ERS-2 (in the same orbit as Envisat-1 and trailing it by about $28 \mathrm{~min}$ ), approached within about $90 \mathrm{~km}$ of the eye of Hurricane Ivan at 0338 UTC and 0406 UTC 15 September (Fig. 1). Both satellites carried radar altimeters that documented wind speed and wave height along their ground track. Also, five NDBC buoys, located within $4^{\circ}$ of the hurricane track (Fig. 1), documented significant wave height time series through the passage of the hurricane. All these data will be used to evaluate our model results.

\section{Hurricane wind field specification}

The wind fields during Hurricane Ivan are obtained from the NOAA/HRD real-time wind analysis (HWIND) and interpolated into 0.5 -h intervals to input into both the WW3 and POM models. HWIND is an integrated tropical 


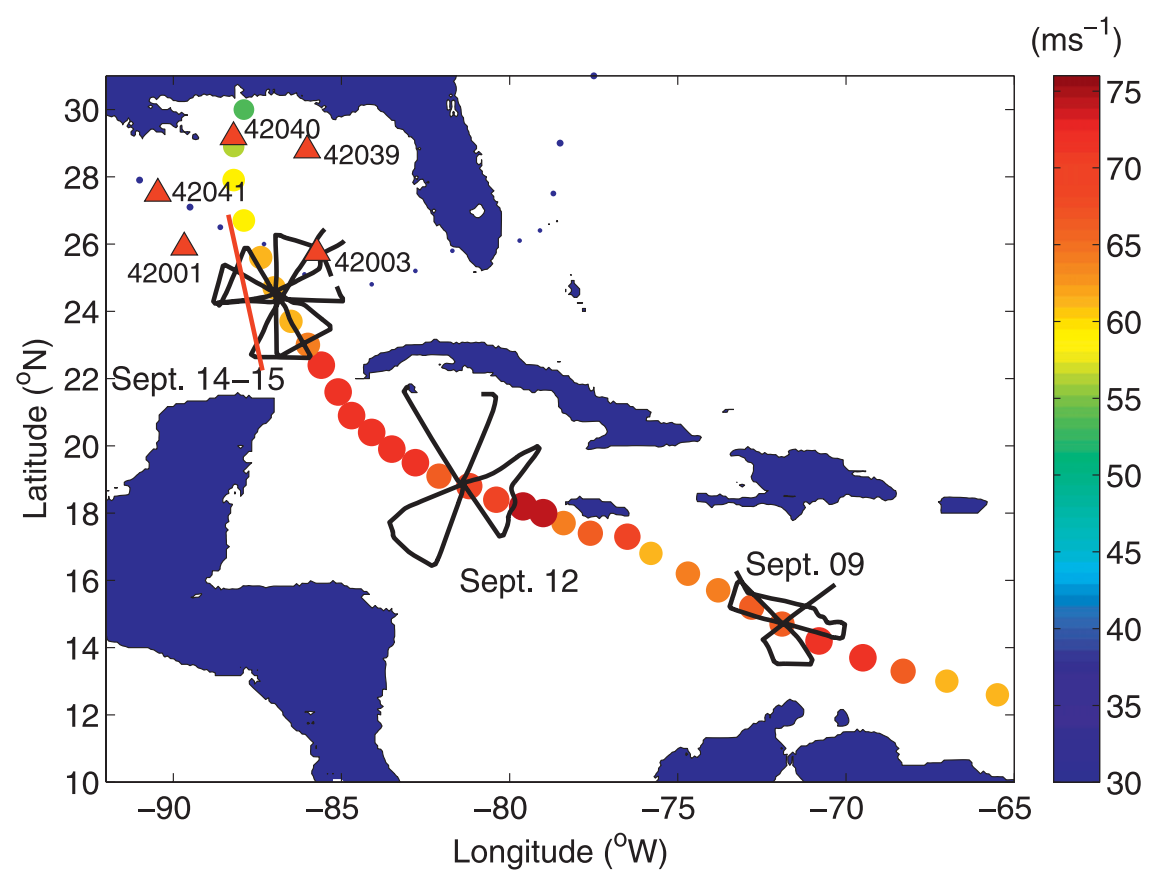

FIG. 1. Available measurements along Hurricane Ivan track. The color and size of the circle represents the maximum wind speed of the hurricane. The black lines in the vicinity of the hurricane track represent the aircraft storm relative flight tracks during the SRA measurements. The red line to the left of the hurricane track, overlapping the 14-15 Sep SRA measurements, shows the satellite tracks of Envisat-1 and ERS-2. The red triangles in the Gulf of Mexico show NDBC buoy locations along Hurricane Ivan track.

cyclone observing system in which wind measurements from a variety of observation platforms are used to develop an objective analysis of the distribution of wind speeds in a hurricane (Powell et al. 1998). The wind data in gridded form are available at the HRD Web site for all hurricanes in the Atlantic basin since 1994 (www.aoml. noaa.gov/hrd/data_sub/wind.html). The HRD winds with the spatial resolution of about $6 \mathrm{~km} \times 6 \mathrm{~km}$, covering an area of about $8^{\circ} \times 8^{\circ}$ in latitude-longitude around the hurricane's center, are provided at intervals of every 3 or $6 \mathrm{~h}$. This frequency is not sufficient to force a numerical model and therefore the wind data need to be interpolated in space and time.

If a hurricane rapidly intensifies or its size undergoes significant changes in a short period of time, direct time/ space interpolation may result in distortion of wind fields. Any error in the input wind field will result in an error in the computed wave field because wind waves are very sensitive to small variations in the wind input. To illustrate this sensitivity, let us consider fully developed wave conditions in which the significant wave height $H_{s}$ is roughly proportional to the square of the wind speed and wave energy is roughly proportional to the wind speed cubed. A $10 \%$ bias in the surface wind speed may cause $\sim 20 \%$ error in $H_{s}$ and $\sim 35 \%$ in wave energy.
Here, we introduce a new interpolation method (hereafter called "normalized interpolation") of the HRD wind fields in time/space with minimum distortions of the hurricane wind field. For simplicity, we illustrate below the normalized interpolation method along one radial direction of the hurricane, which can easily be applied to a 2D hurricane wind field. Consider two radial profiles of wind speed $\mathrm{W} 1(\mathrm{R} 1)$ and $\mathrm{W} 2(\mathrm{R} 2)$ at two different times $t_{1}$ and $t_{2}$ with their maximum wind speed located at R1 and R2 correspondingly (Fig. 2a). A simple averaging of the two profiles at time $\left(t_{1}+t_{2}\right) / 2$ would result in the dashed line in Fig. 2a, which is clearly not a good approximation of the hurricane radial wind profile. In our method we first normalize the radial distance from the hurricane center by the radius of the maximum wind speed, so that in the normalized coordinate, both $\mathrm{W} 1$ and $\mathrm{W} 2$ have their maximum wind speed at the normalized distance 1.0 (Fig. 2b). If we interpolate these two wind profiles at time $\left(t_{1}+t_{2}\right) / 2$ (dashed line in Fig. 2b), the wind profile is not distorted like the one in Fig. 2a. Since the radius of the maximum wind speed for the interpolated wind profile is simply $(\mathrm{R} 1+\mathrm{R} 2) / 2$, we use this radius to obtain the desired interpolated wind speed profile at time $\left(t_{1}+t_{2}\right) / 2$ in the dimensional coordinate as illustrated by the dashed line 
(a)

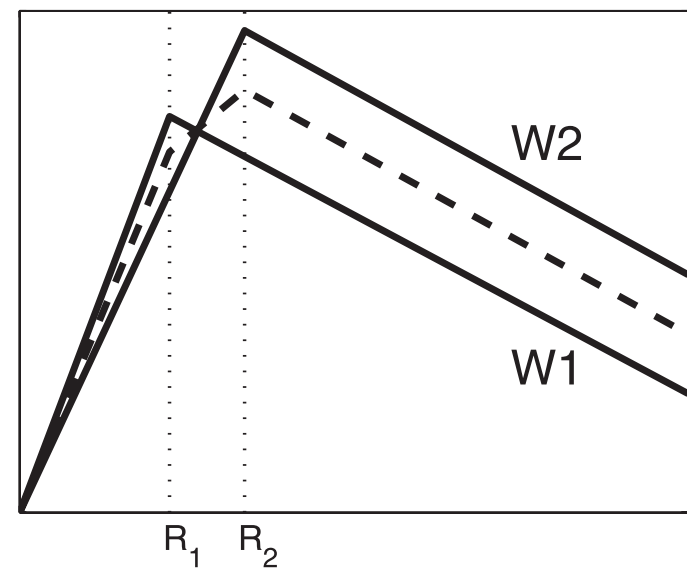

(c)

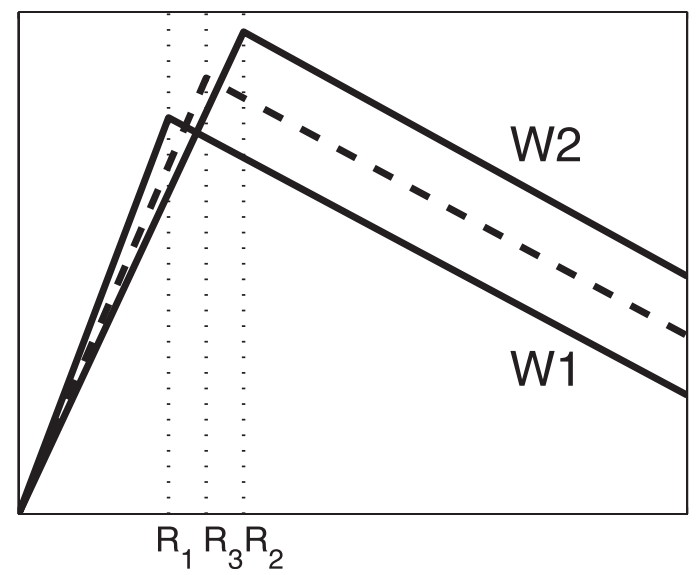

in Fig. 2c. An example of the 2D interpolated wind field at 1800 UTC 9 September and the HRD winds at 1330 and 1930 UTC 9 September is shown in Fig. 3.

\section{Results and discussion}

\section{a. Wave parameters}

We first compare the $H_{s}$, dominant wavelength (DWL), and dominant wave propagation direction (DWD) in WW3 with the SRA measurements. The $H_{s}$ is the standard output of the wave model. To obtain the DWL and DWD, the model directional frequency spectrum is transformed into the same wavenumber space as the SRA measurements using Jacobian transformation, and the location of the wave spectrum peak, which corresponds to the DWL and DWD, is determined using a parabolic interpolation. The DWL, DWD, and $H_{s}$ are interpolated from the uniform model grid in WW3 to the nonuniformly spaced SRA measurement locations using (b)

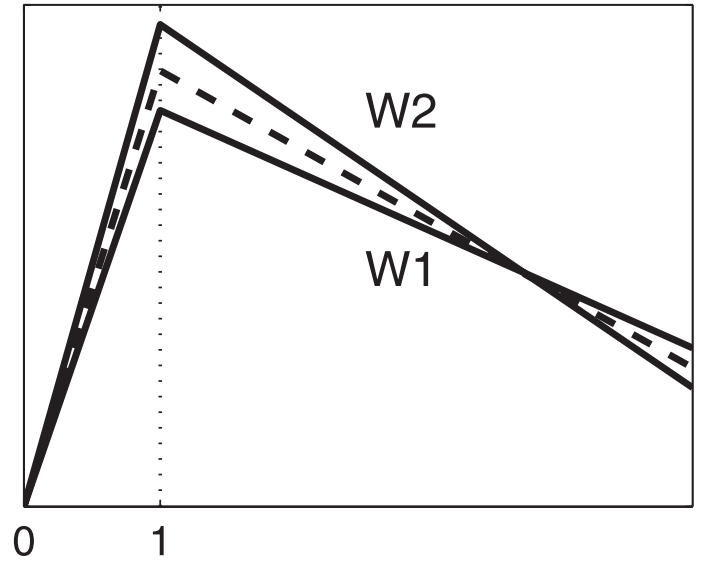

FIG. 2. Diagrams of wind profile interpolations. (a) Solid lines are wind profiles $\mathrm{W} 1$ and $\mathrm{W} 2$ vs radial distance at times $t_{1}$ and $t_{2}$ with maximum wind speed at $\mathrm{R}_{1}$ and $\mathrm{R}_{2}$; dashed line is wind profile obtained at time $\left(t_{1}+t_{2}\right) / 2$ using direct time/space interpolation. (b) Solid lines are wind profiles $\mathrm{W} 1$ and $\mathrm{W} 2$ vs radial distance normalized by the radius of maximum wind at times $t_{1}$ and $t_{2}$; dashed line is wind profile obtained at time $\left(t_{1}+t_{2}\right) / 2$ using normalized interpolation. (c) Solid lines are wind profiles $\mathrm{W} 1$ and $\mathrm{W} 2$ vs radial distance at times $t_{1}$ and $t_{2}$ with maximum wind speed at $\mathrm{R}_{1}$ and $\mathrm{R}_{2}$; dashed line is wind profile obtained at time $\left(t_{1}+t_{2}\right) / 2$ using normalized interpolation.

the cubic interpolation method. For each SRA location, these parameters are then linearly interpolated in time to obtain the DWL, DWD, and $H_{s}$ at the measurement time.

Comparisons between the model results in experiments A, B, and C and the observations at all the SRA measurement locations along the flight tracks are shown in Fig. 4 for the measurements on 9 September, Fig. 5 for the measurements on 12 September, and Fig. 6 for the measurements on 14-15 September. The model significant wave height and the dominant wavelength in experiments $\mathrm{A}, \mathrm{B}$, and $\mathrm{C}$ are plotted in Fig. 7 against the corresponding SRA data for all SRA measurement locations for the periods of 9, 12, and 14-15 September. The root-mean-square errors, defined as rmse = $\sqrt{1 / N \Sigma\left(x_{\text {Model }}-x_{\text {Observation }}\right)^{2}}$, between the SRA measurements and the model results are presented in Table 1.

The model DWDs in all three experiments are very close to each other and match very well with the 

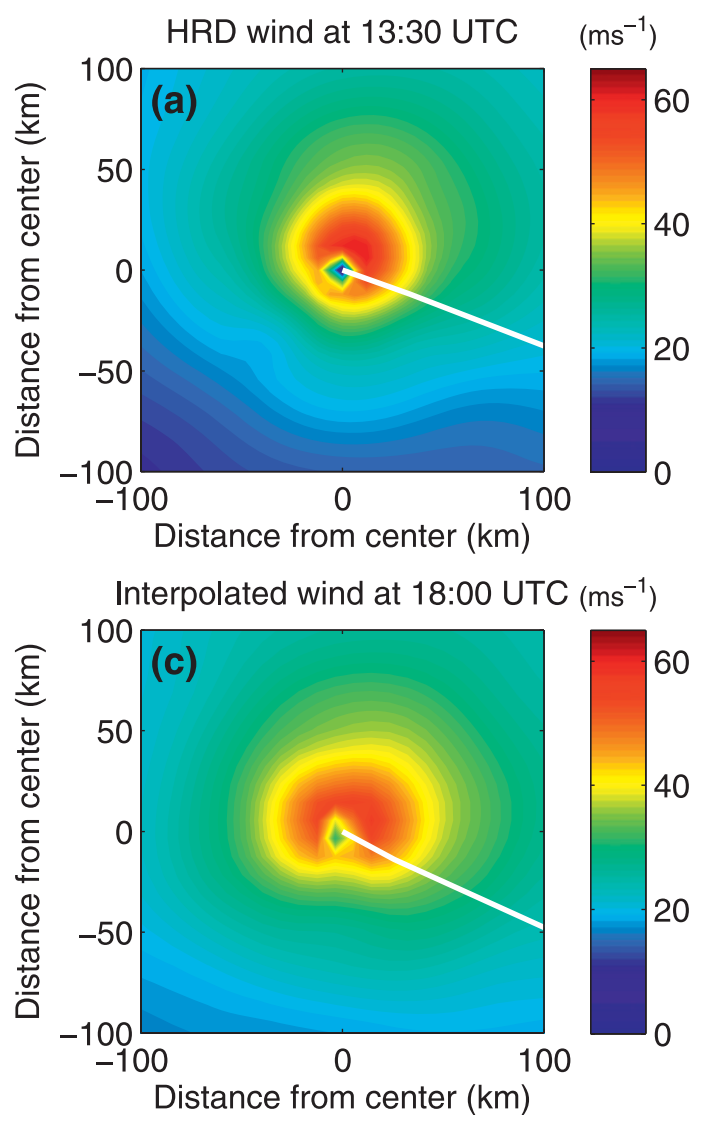

SRA observations during all three flight periods (Figs. $4 \mathrm{~b}, 5 \mathrm{~b}$, and $6 \mathrm{~d})$. This indicates that the wind stress parameterization-based CWW model and wave-current interaction have negligible effects on the DWD predictions. The locations where the wave propagation directions differ by more than $10^{\circ}$ are generally in the rear right quadrant of the hurricane where there can be two or three comparable peaks in the observed spectrum while the model spectrum has a smooth, one-peak structure.

From the $H_{s}$ comparison along the flight track on 9 September, we can see that at the locations in the rear quadrants of the hurricane, where the $H_{s}$ values are small (less than $5 \mathrm{~m}$ ), the model predictions in experiment A agree very well with the SRA observations (Figs. 4d, 7a). This is consistent with the fact that WW3 has been extensively calibrated and validated under low and moderate wind conditions. The $H_{s}$ values from experiments $\mathrm{B}$ and $\mathrm{C}$ are also very similar to those from experiment $\mathrm{A}$ at these locations (Fig. 4d), indicating that neither the new wind stress parameterization nor the wave-current interaction has any effect when the waves are small.

Along the other flight track sections during the 9 September flight and the entire flight on 12 and 14-15 Sep-

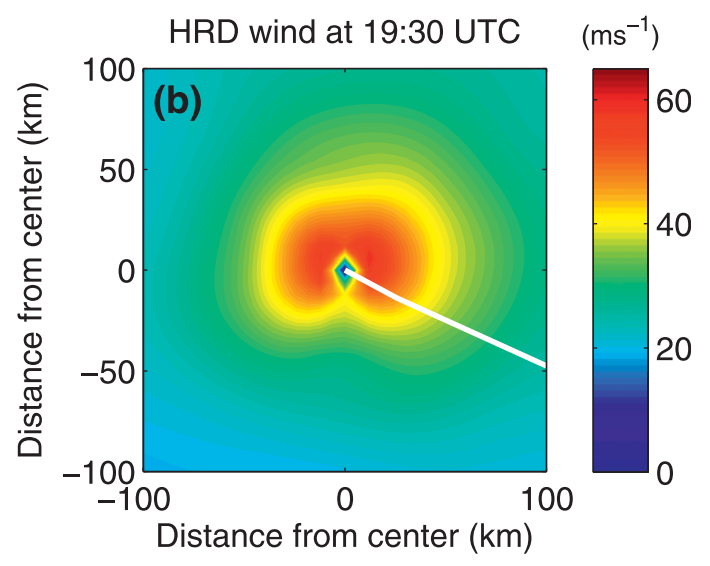

FIG. 3. HRD wind speed within $100 \mathrm{~km}$ of the hurricane center at (a) 1330 UTC 9 Sep and (b) 1930 UTC 9 Sep. (c) The interpolated wind field at 1800 UTC 9 Sep. The white line in the figures shows the hurricane track, and the color scale gives the magnitude of wind speed.

tember, the results show that experiment A significantly overestimates $H_{s}$ almost everywhere (Figs. 4d, 5d, and 6d), and the error increases as $H_{s}$ increases (Fig. 7a). The $H_{s}$ prediction in experiment $\mathrm{B}$ is generally lower compared to experiment A. Take the 9 September flight, for example; the root-mean-square error of $H_{s}$ in Table 1 is reduced from $2.25 \mathrm{~m}$ in experiment $\mathrm{A}$ to $1.67 \mathrm{~m}$ in experiment $\mathrm{B}$ (the reduction is about $26 \%$ ). This is because the new parameterization reduces the wind stress at higher wind speeds, and hence reduces the wind input to waves in the model. However, the $H_{s}$ values are still considerably larger than observations (Fig. 7b).

When the ocean current is introduced to the wave model in experiment $\mathrm{C}$, the root-mean-square error is further reduced to $0.9 \mathrm{~m}$ for the 9 September flight (about $60 \%$ error reduction), the overall agreement with the observations is significantly improved, and the systematic overprediction for high wind speeds has been removed (Fig. 7c). This is consistent with the finding in Fan et al. (2009a). They investigated the surface wave and ocean current responses under idealized tropical cyclones, and also found that the wave-current interaction tends to significantly reduce the magnitude of simulated $H_{s}$. In the next subsection, a detailed analysis is given to 

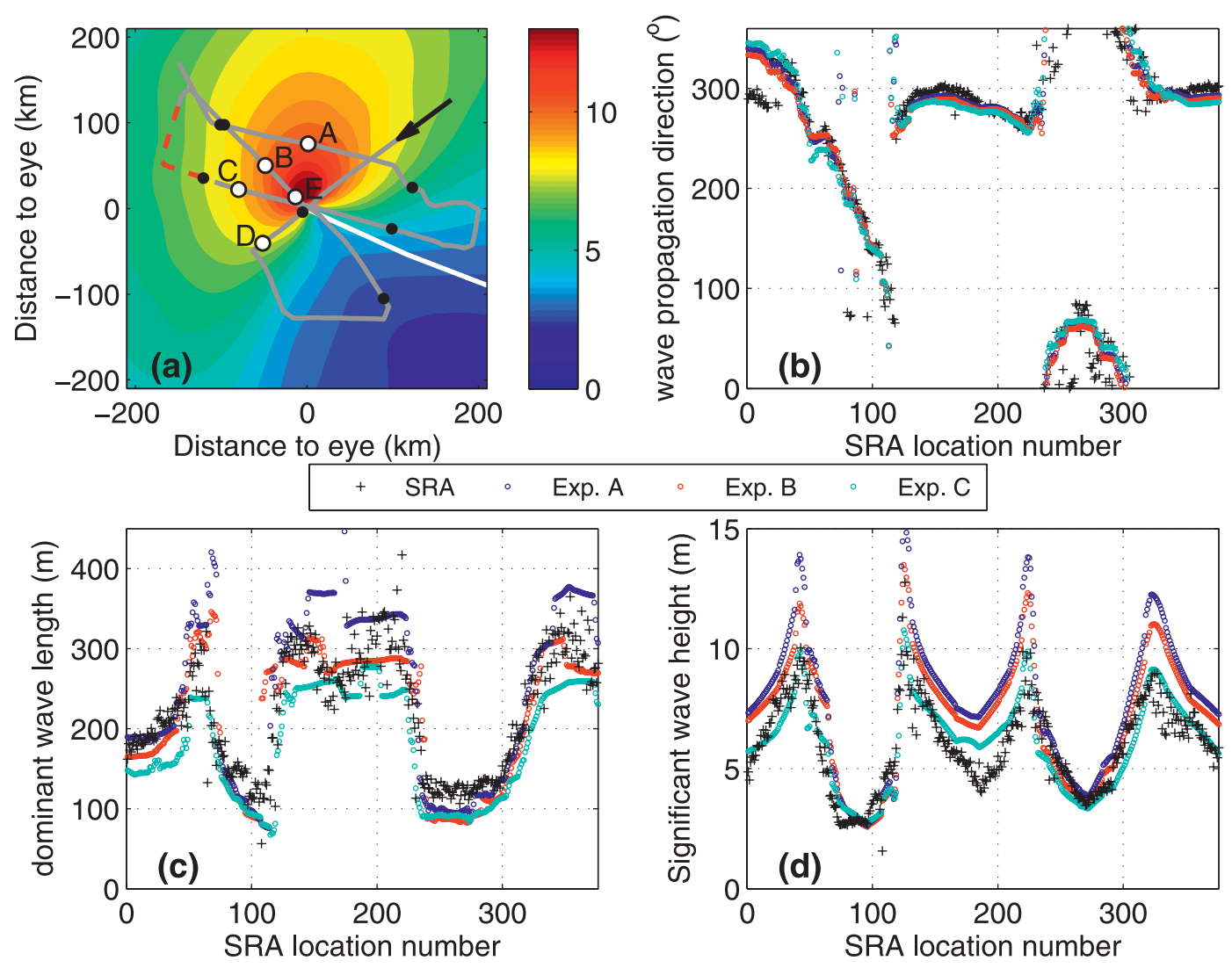

FIG. 4. (a) Significant wave height field (m, color) at 1800 UTC 9 Sep. The thick white line is the hurricane track and thick gray line is the flight track. The black arrow shows the start point and direction of the flight, and the black dots shows the SRA location in an increment of every 50 data points from the start. (b) Wave propagation direction relative to true north rotating clockwise, (c) dominant wavelength, and (d) significant wave height comparison between SRA measurements and model results in experiments A, B, and C.

explain why ocean currents tend to reduce $H_{s}$ under tropical cyclone conditions.

The $H_{s}$ comparison for the 9 September flight in Fig. $4 \mathrm{~d}$ shows that the results from experiment $\mathrm{C}$ almost overlap with the observations everywhere except for a small section along the flight track in front of the hurricane (shown by the red dashed line in Fig. 4a). Although the $H_{s}$ prediction is significantly improved in this section compared to experiments $\mathrm{A}$ and $\mathrm{B}$, the differences between the model results and observations are still significant. Furthermore, the $H_{s}$ comparison along the 12 September flight also showed large differences between the model results from experiment $\mathrm{C}$ and observations along most sections of the flight track. However, the $H_{s}$ comparison for the 14-15 September flight does not seem to have this problem. This discrepancy could be due to the influence of the preexisting mesoscale variability of the ocean current in the Caribbean Sea on surface waves, which is not considered in this study. Our ocean model initialization methodology provides a realistic representation of the Loop Current and mesoscale eddies in the Gulf of Mexico, but no real-time data assimilation is done in the Caribbean Sea. Instead, the GDEM monthly climatology data are used to initialize the 3D temperature and current fields. Since the climatology data smooth out most of the mesoscale features, the modeled current field also shows a smooth structure in the Caribbean area. The effect of mesoscale features, such as the Loop Current and a warm-core ring in the Gulf of Mexico, on the wave predictions will be discussed in detail in section $5 \mathrm{~d}$.

The model results in all three experiments indicate consistent underestimation of $H_{s}$ within the hurricane eye region, except on 9 September when the radius of maximum wind was small $(13 \mathrm{~km})$ and Hurricane Ivan was moving with a relatively fast forward speed $\left(6 \mathrm{~m} \mathrm{~s}^{-1}\right)$. On 14-15 September, when the radius of maximum wind was 3 times larger $(39 \mathrm{~km})$ and Ivan was moving about 3 times slower $\left(2 \mathrm{~m} \mathrm{~s}^{-1}\right)$, significant downward excursions in the model $H_{s}$ for each of the six times the aircraft 

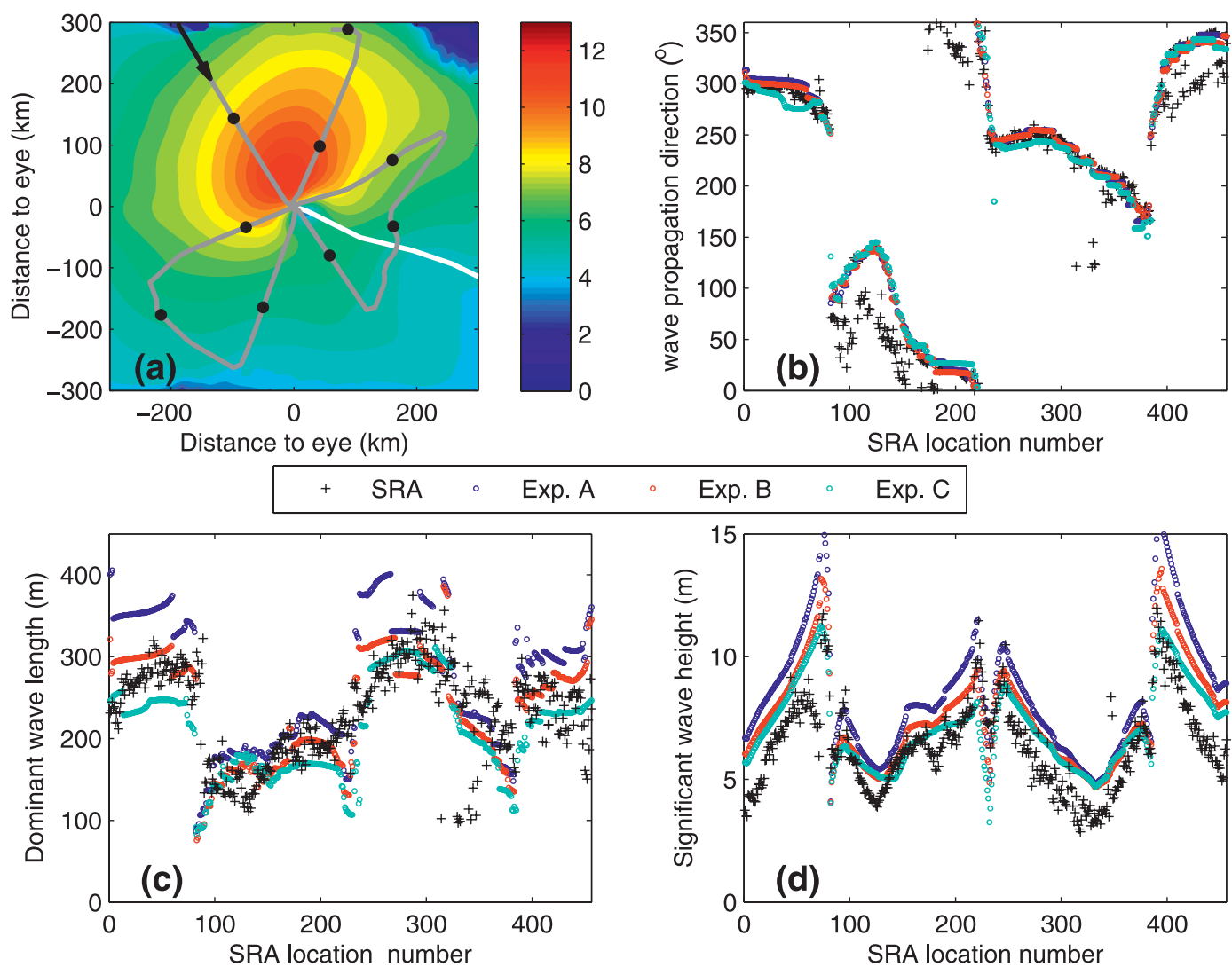

FIG. 5. SRA observations and WW3 results comparison for experiments A, B, and C for 12 Sep flight. (a) Significant wave height field (m, color) at 1300 UTC 12 Sep. The thick white line is the hurricane track and the thick gray line is the flight track. The black arrow shows the start point and direction of the flight, and the black dots show the SRA location in an increment of every 50 data points from the start. (b) Wave propagation direction relative to true north rotating clockwise, (c) dominant wavelength, and (d) significant wave height comparison between SRA measurements and model results from experiments $\mathrm{A}, \mathrm{B}$, and $\mathrm{C}$.

passed through the eye are shown (Figs. 6d, 14). We speculate that a possible reason for the degraded $H_{s}$ predictions near the hurricane eye might be the not very accurate representation of the inflow angle in the HRD surface wind fields in these instances. From idealized experiments (not shown here), we found that variations of the inflow angle in the surface wind have a very small effect on the surface wave prediction when the hurricane has a small eye and moves relatively fast, like Hurricane Ivan on 9 September. But for slowly moving hurricanes with large eyes, the $H_{s}$ prediction can be significantly affected by even small changes in the wind inflow angle. HRD surface wind analysis is based on available surface wind observations from buoys, Coastal-Marine Automated Network (CMAN) platforms, ships, and other surface facilities. Because these data are often sparse near hurricanes, aircraft flight-level observations adjusted to the surface with a planetary boundary layer model (Powell 1980) are used to supplement the in situ surface measurements. Based on examination of the in- flow angle change from the launch levels to the surface, the wind directions in HWIND for surface-adjusted flight-level winds over water are given a constant angle of about $20^{\circ}$ (Powell et al. 1996). It is possible that the real inflow angles in the Ivan surface wind field near the eyewall were quite different from the values assigned by HWIND.

The model $H_{s}$ from all three different experiments is also compared with NDBC buoy data from 13 to 16 September in the Gulf of Mexico (Fig. 8). Overall, the WW3 simulations show good agreement with observations. At buoys 42003 and 42039, WW3 with the original $C_{d}$ parameterization (experiment $\mathrm{A}$ ) overestimates the maximum $H_{s}$ by about $1.5-2 \mathrm{~m}$, while the simulations in experiments B and C yield much reduced errors. Buoy 42040 was adrift after 2100 UTC 15 September, which introduces some uncertainty in the accuracy of the comparison with the data. Over all, despite the buoy drift, the observations are in reasonably good agreement with the model predictions. On 15 September, Hurricane 

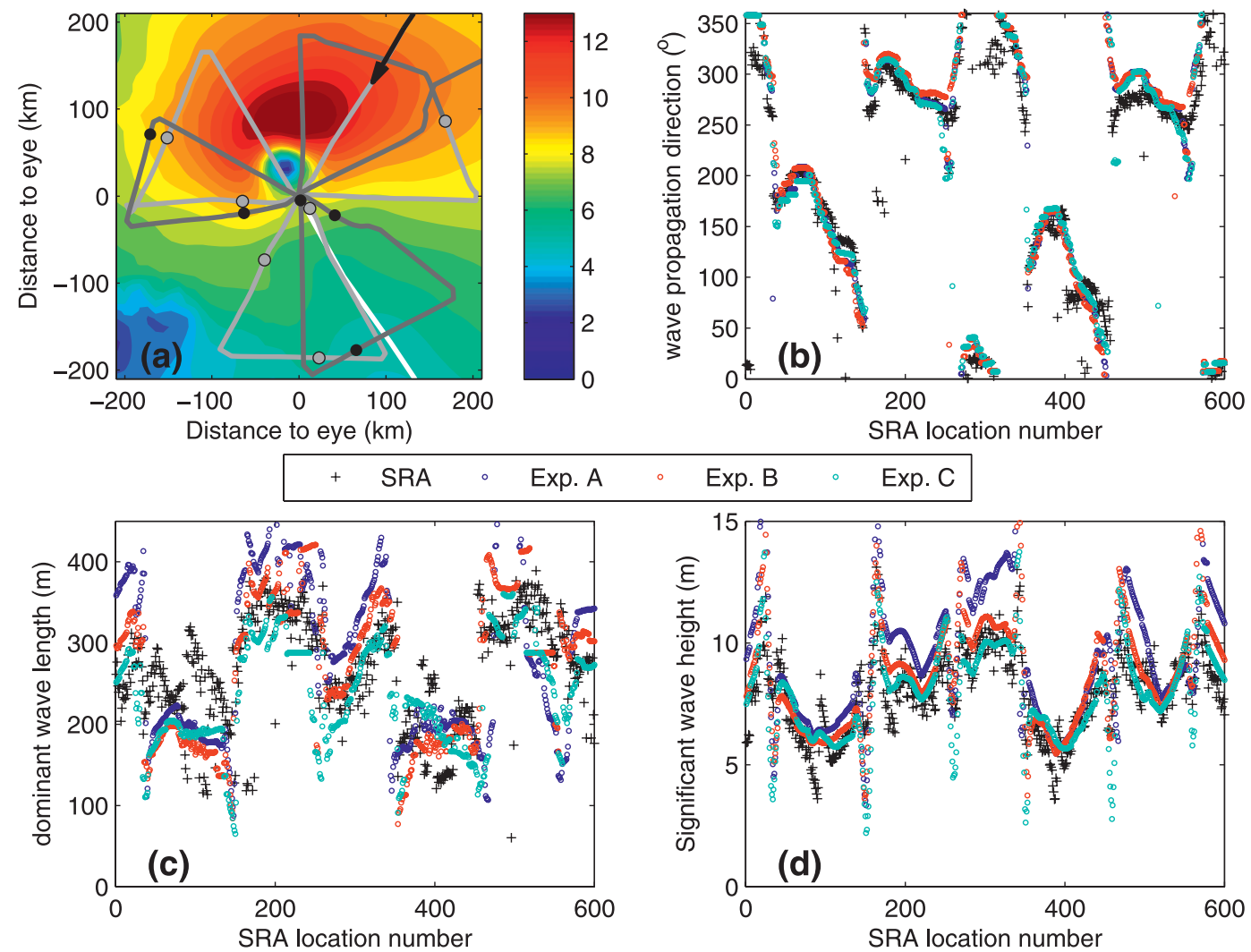

FIG. 6. SRA observations and WW3 results comparison for experiments A, B, and C for 14-15 Sep flight. (a) Significant wave height field (m, color) at 0200 UTC 15 Sep. The thick white line is the hurricane track. The thick light gray line is the flight track from SRA location 1-300, and the dark gray line is the flight track from SRA location number 300-600. The black arrow shows the start point and direction of the flight, and the gray (black) dots show the SRA locations in an increment of every 50 data points from the start (number 350) on the light gray (dark gray) track. (b) Wave propagation direction relative to true north rotating clockwise, (c) dominant wavelength, and (d) significant wave height comparison between SRA measurements and model results from experiments A, B, and C.

Ivan passed directly over six wave-tide gauges deployed by the Naval Research Laboratory north of buoy 42040 $\left(\sim 29.3^{\circ} \mathrm{N}, 87^{\circ} \mathrm{W}\right)$. Three buoys observed waves with $H_{s}$ reaching maximum values of 17.9,16.1, and $17.1 \mathrm{~m}$ (Wang et al. 2005). These values are in good agreement with the model-produced $H_{s}$ in experiment $\mathrm{C}$, as seen in the significant wave height wave swath (Fig. 10).

Figure 9 shows $H_{s}$ measured by the radar altimeters on the Envisat-1 and ERS-2 satellites at 0338 and 0406 UTC 15 September, respectively (tandem track shown in Fig. 1), compared with WW3 results from experiment C at 2200 UTC 14 September and 0200 and 0400 UTC 15 September. The open circles show SRA $H_{s}$ observations between 2104 UTC 14 September and 0257 UTC 15 September, which were within $10 \mathrm{~km}$ of the satellite track. The simulated $H_{s}$ on 15 September, the closest time to the satellite measurements, compares well to the satellite data, although the altimeter shows higher maximum $H_{s}$ values by 1-2 m compared to both the model results and SRA data. The satellite observations and model predictions in Fig. 9 indicate spatial variations at particular times. The spatial variation of the SRA data, collected over a 6-h interval, should not be expected to match any particular model curve. For example, the four SRA data points clustered near $170 \mathrm{~km}$ and $6.6 \mathrm{~m}$ were acquired at about 2235 UTC 14 September. They are slightly above the dotted model curve for 2200 UTC. On the other hand, the three SRA data points clustered at about $150 \mathrm{~km}$ and $8 \mathrm{~m}$ were acquired at about 0220 UTC 15 September and are quite close to the dashed model curve for 0200 UTC. The comparison between the predicted $H_{s}$ and satellite measurements confirms that including wave-current interaction improves wave forecast skill.

The swath pictures of $H_{s}$ in all three experiments are shown in Fig. 10 and represent maximum values at each grid point throughout the hurricane passage. In this figure, results at shallow-water seas below 30-m depth are removed because of limitations of the resolving depth in the wave model. It is seen that the highest 

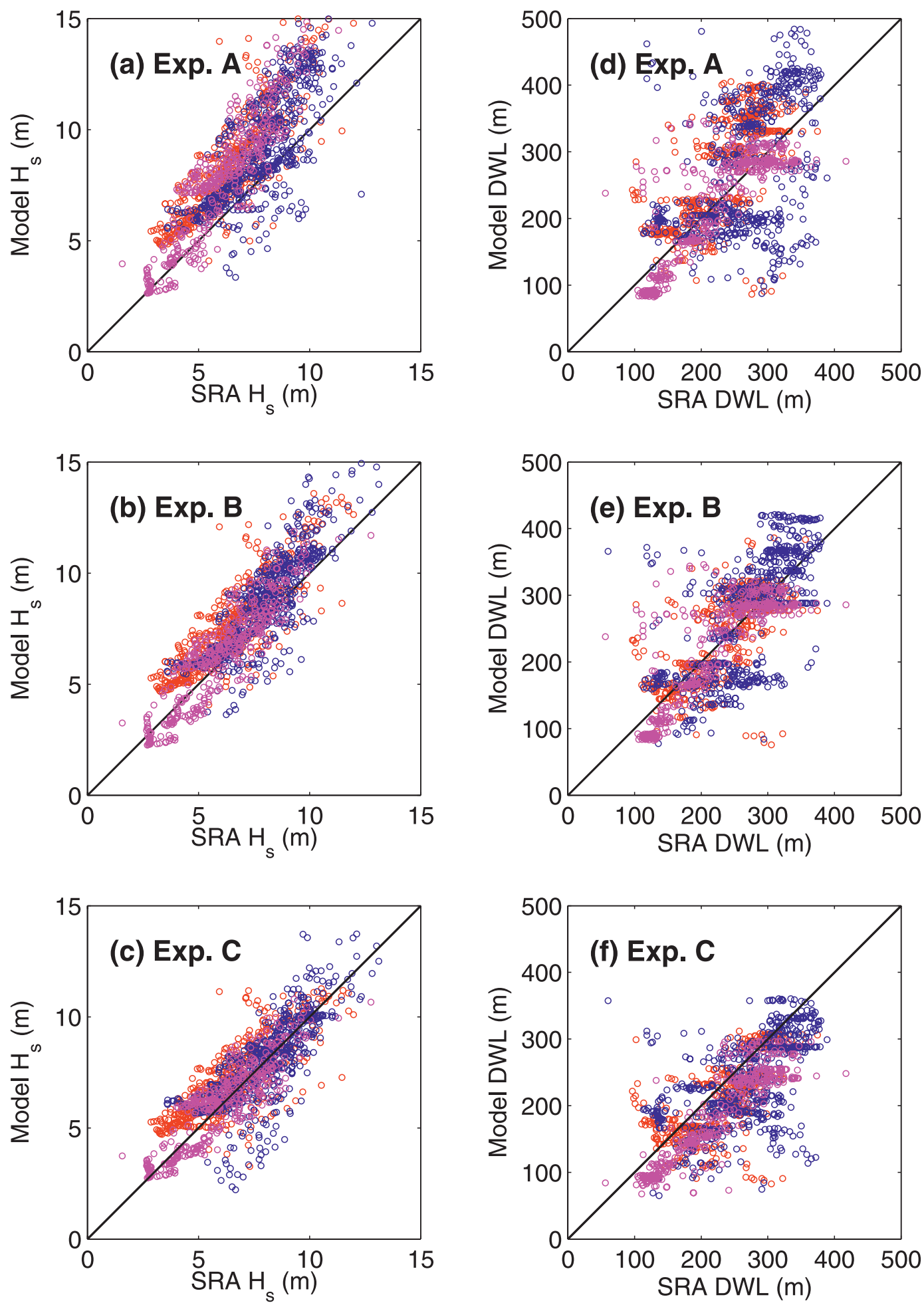

FIG. 7. Model $H_{s}$ vs SRA measurements for (a) experiment A, (b) experiment B, and (c) experiment C; and model DWL vs SRA measurements for (d) experiment A, (e) experiment B, and (f) experiment C. The magenta, red, and blue circles correspond to the calculation period of 9, 12, and 14-15 Sep, respectively. 
TABLE 1. Rmse of model $H_{s}$, DWL, and DWD relative to the SRA observation. The rmse is defined in section 5a.

\begin{tabular}{|c|c|c|c|c|}
\hline & Parameter (unit) & Expt A & Expt B & Expt $\mathrm{C}$ \\
\hline \multirow[t]{3}{*}{9 Sep } & $H_{s}(\mathrm{~m})$ & 2.25 & 1.67 & 0.90 \\
\hline & DWL (m) & 68.66 & 51.81 & 55.32 \\
\hline & DWD $\left(^{\circ}\right)$ & 31 & 31 & 31 \\
\hline \multirow[t]{3}{*}{$12 \mathrm{Sep}$} & $H_{s}(\mathrm{~m})$ & 2.41 & 1.62 & 1.38 \\
\hline & DWL (m) & 71.06 & 50.80 & 52.46 \\
\hline & DWD $\left(^{\circ}\right)$ & 30 & 31 & 32 \\
\hline \multirow[t]{3}{*}{ 14-15 Sep } & $H_{s}(\mathrm{~m})$ & 2.39 & 1.46 & 1.27 \\
\hline & DWL (m) & 100.84 & 67.18 & 69.82 \\
\hline & DWD $\left(^{\circ}\right)$ & 38 & 39 & 38 \\
\hline
\end{tabular}

waves are found when Ivan reached SSHS category 5 intensity in the northern Caribbean and when the hurricane approached shallow seas before making landfall. The values of $H_{s}$ in the swaths produced in experiments $\mathrm{B}$ and $\mathrm{C}$ are progressively lower than those in experiment $\mathrm{A}$. The difference plot between experiment $\mathrm{A}$ and experiment $\mathrm{C}$ shows that the larger reduction of $H_{s}$ appears to the right of the hurricane along its track. The maximum difference reached $5.7 \mathrm{~m}$ northwest of Cuba where Ivan passed over the Loop Current. The effect of the Loop Current on wave prediction is discussed below.
The DWL model results show very similar values among all three experiments when the wave field is less developed in the rear left quadrant of the hurricane (Figs. $4 c, 5 c, 6 c$ ). The same tendency was found for the $H_{s}$ simulations. Unlike the $H_{S}$ results, however, the dominant wave lengths are noticeably shorter than those in the SRA measurements. To the right of the hurricane, where the waves are more developed, the three experiments yield very different DWL values (Figs. 4c, 5c, 6c). In experiment A, DWL are mostly longer than those in the SRA observations (Fig. 7d), while in experiment $C$ they are shorter (Fig. 7f).
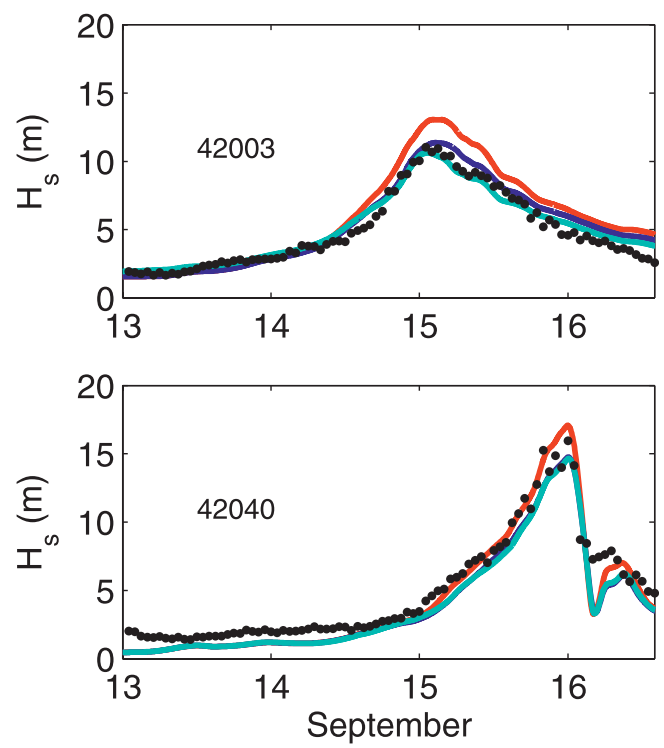

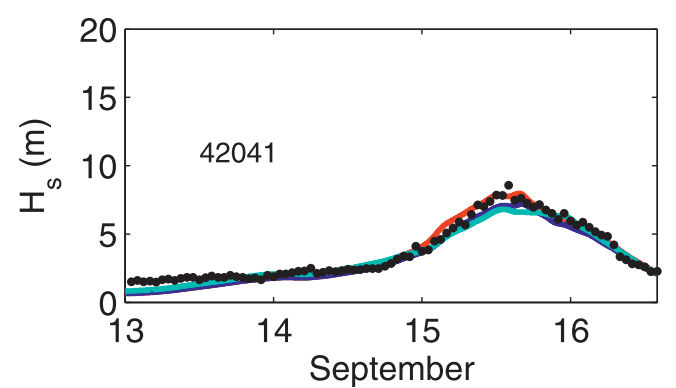

FIG. 8. Comparison of model $H_{s}$ for experiments A, B, and C with NDBC buoy measurements shown in Fig. 1. 


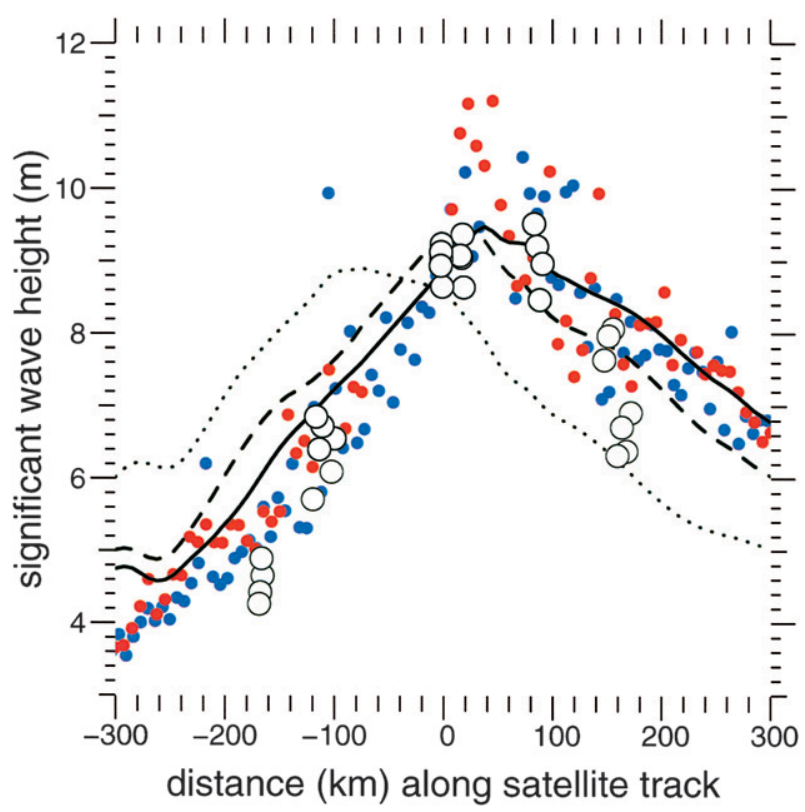

FIG. 9. Significant wave height measured by the radar altimeters on the Envisat-1 (red dots) and ERS-2 (blue dots) satellites at 0338 and 0406 UTC, respectively, on 15 Sep (tandem track shown in Fig. 1) compared with WW3 results from experiment $\mathrm{C}$ at 2200 UTC 14 Sep (dotted line) and at 0200 UTC (dashed line) and 0400 UTC (solid line) $15 \mathrm{Sep}$. The open circles show SRA wave height observations between 2104 UTC 14 Sep and 0257 UTC 15 Sep that were within $10 \mathrm{~km}$ of the satellite track.

Overall, WW3 seems to underestimate DWL when $H_{s}$ is correctly predicted. Fan et al. (2009b, manuscript submitted to J. Phys. Oceanogr.) have also noticed this tendency when their results are compared with DWL empirical formulas from other studies. The underestimation of DWL is most likely due to the nonlinear wave interaction term calculated within WW3. The deficiencies of the discrete interaction (DIA) are discussed in detail in Vledder et al. (2001). Tolman (2004; H. Tolman 2008, personal communication) also shows that the present WW3 nonlinear interaction calculation based on the DIA systematically overestimates the wind sea spectral peak frequency by roughly $10 \%$ (i.e., underestimates the DWL of wind seas by roughly $20 \%)$. For swell, such biases are not obvious in WW3.

\section{b. Reduction of significant wave height by ocean currents}

A significant finding in the previous section is that inclusion of the ocean current systematically reduces $H_{s}$ prediction. There are two ways the ocean current impacts the wave field as described in the methodology section, that is, the subtraction of the current vector from the 10-m wind vector, and the modification of the wave action equation. Both effects are included in experiment $C$. To determine which current effect is more important, experiment $\mathrm{D}$ is designed. This experiment is the same as experiment $C$, except the effect of current in the wave action equation is not considered. The results of the wave field simulation corresponding to the time/location of the SRA measurement at 1800 UTC 9 September are presented in Fig. 11. Even though we presented a snapshot in Fig. 11, these results are very representative throughout the whole flight period.

Starting from experiment B (without current effects), if the 10-m wind speed input is modified by the current but the wave action equation is not affected (experiment D), the resulting simulation of $H_{s}$ indicates small changes, as seen in Fig. 11d. Notice that $H_{s}$ is reduced in the area where the wind and current vectors have similar directions and increased where the wind and current vectors misaligned, as seen from Figs. 11b and $11 \mathrm{~d}$. When the current effect in the wave action equation is also included (experiment C), $H_{s}$ is significantly reduced, especially where $H_{s}$ reaches its maximum, as shown in Fig. 11c. These figures clearly indicate that the current effect on the wave field is mainly through the wave action equation. The relative wind speed effect is significantly smaller.

Let us next examine why including the ocean current in the wave action equation tends to reduce $H_{s}$. Since the direction of the dominant wave is mostly within $30^{\circ}$ of the direction of the current (Figs. 11, 12), we can consider for simplicity a one-dimensional approximation of the wave action equation. Furthermore, the wave action equation is expressed in the coordinate system moving with the hurricane, and the time tendency term is neglected (i.e., the wave field is assumed stationary in the moving coordinate). Then, the wave action equation used in experiment $\mathrm{C}$ [Eq. (1)] is simplified to

$$
\frac{\partial N}{\partial s}\left(U_{c}+C_{g}-U_{t}\right)-k \frac{\partial N}{\partial k} \frac{\partial U_{c}}{\partial s}=F
$$

where $C_{g}$ is group velocity and $U_{t}$ is the hurricane translation speed projected onto the wave propagation direction $s$. If we only consider the current effect on relative wind speed (experiment D), then (2) is further simplified to

$$
\frac{\partial N_{0}}{\partial s}\left(C_{g}-U_{t}\right)=F_{0}
$$

where the subscript 0 in $N$ and $F$ denotes no current. Subtracting (2) from (3) yields 


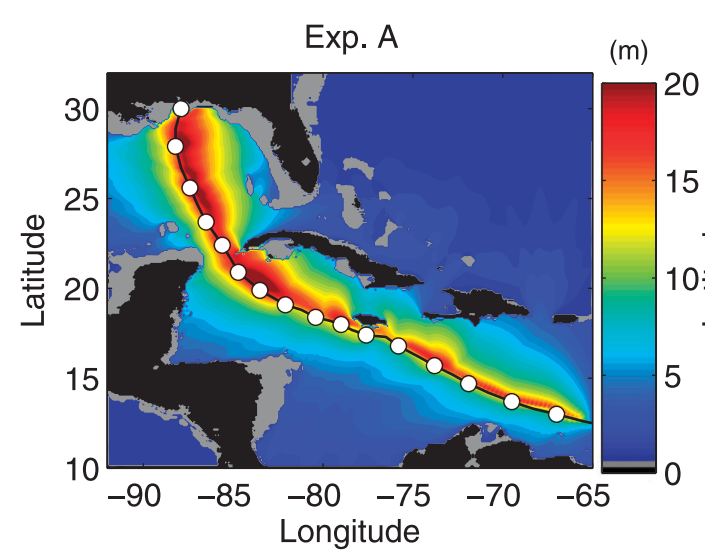

(m)

Exp. B

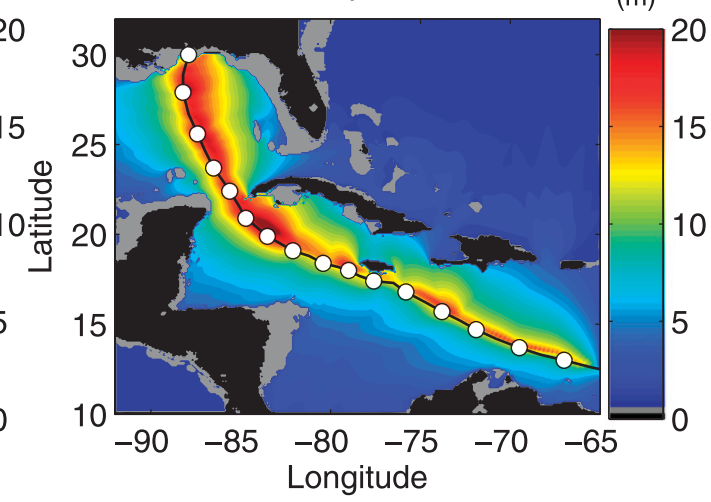

(m)

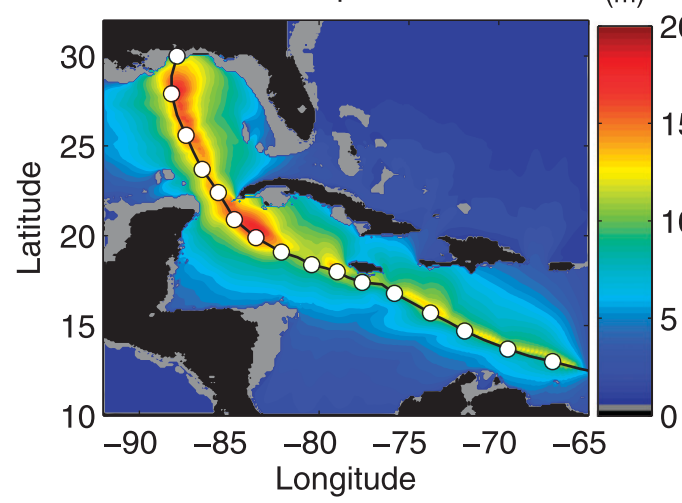

Exp. A - Exp. C

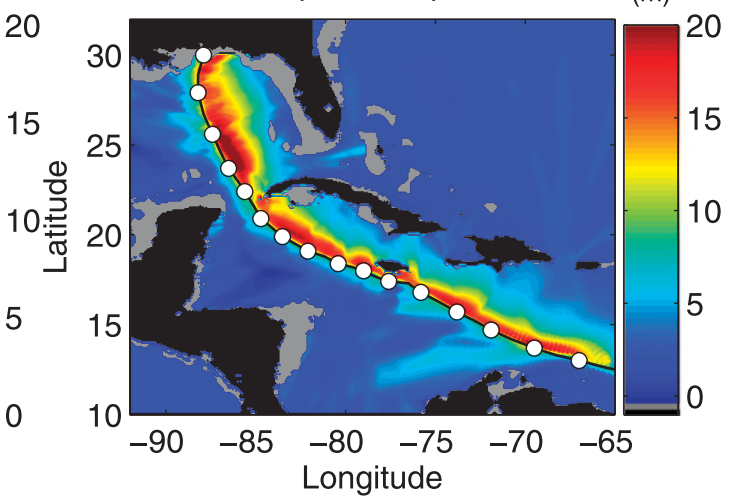

FIG. 10. Swaths of $H_{s}$ produced by WW3 in experiment A, experiment B, and experiment $\mathrm{C}$ and the difference of the swath of $H_{s}$ between experiment $\mathrm{A}$ and experiment $\mathrm{C}$ during the passage of Hurricane Ivan. The solid line is the storm track with dots indicating the positions of the storm center every $12 \mathrm{~h}$. Gray colors represent shallow-water seas below 30-m depth.

$\frac{\partial\left(N_{0}-N\right)}{\partial s}\left(C_{g}-U_{t}\right)=-k \frac{\partial N}{\partial k} \frac{\partial U_{c}}{\partial s}+\frac{\partial N}{\partial s} U_{c}+\left(F_{0}-F\right)$

Then, Eq. (4) shows that the reduction of the wave action spectrum $\left(N_{0}-N\right)$ from experiment $\mathrm{D}$ to experiment $\mathrm{C}$, shown in Fig. 11c, is caused by three factors. First, when waves are compressed or stretched by a spatially varying current, the resulting modulation of the wave action is expressed by the term $-k(\partial N / \partial k)\left(\partial U_{c} / \partial s\right)$. Second, the term $(\partial N / \partial s) U_{c}$ is the modulation to the wave field due to horizontal current advection. This term can be interpreted as follows: if the forcing term is set such that the wave field grows with fetch $(\partial N / \partial s>0)$, then the spatial wave growth is reduced by a positive current simply because the wave packet propagates faster. The third effect is the modification of the forcing term $\left(F_{0}-F\right)$, which is expected to be more important for shorter waves (spectral tail).

Let us consider a wave pathway (pink arrow) in Fig. 11. Along this path the reduction of $H_{s}$ [i.e., $\left(N_{0}-N\right)$ near the spectral peak] rapidly increases (Fig. 11c). Along the same path, $H_{s}$ (and therefore $N$ near the spectral peak) increases (Fig. 11a) and the ocean current $\mathbf{U}_{c}$ remains large (Fig. 11b). After close examination of the spectral output along this path (not shown), we have found that the compression/stretching term is relatively unimportant near the spectral peak and that the advection term $(\partial N / \partial s) \mathbf{U}_{c}$ is mainly responsible for the reduction of the significant wave height (i.e., waves become lower when the wave group propagates faster because of the positive ocean current). We have also examined the magnitude of all terms in the full (2D) wave action equation, and have confirmed that the advection term along the wave propagation is dominant over a large area where the current is strong and roughly aligned with the wave propagation direction, yielding the significant reduction of $H_{s}$.

This analysis also highlights the significance of the hurricane translation speed $U_{t}$. Equation (4) indicates that the reduction of $N$ is enhanced as $\left(C_{g}-U_{t}\right)$ decreases (i.e., as the translation speed increases). In fact, 
(m)

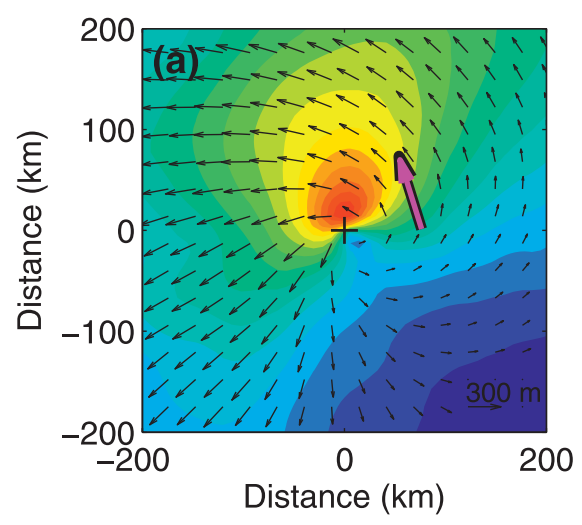

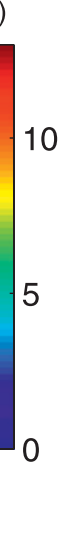

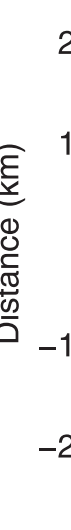

(m)

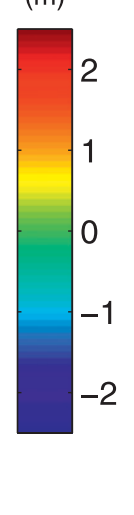

(m)

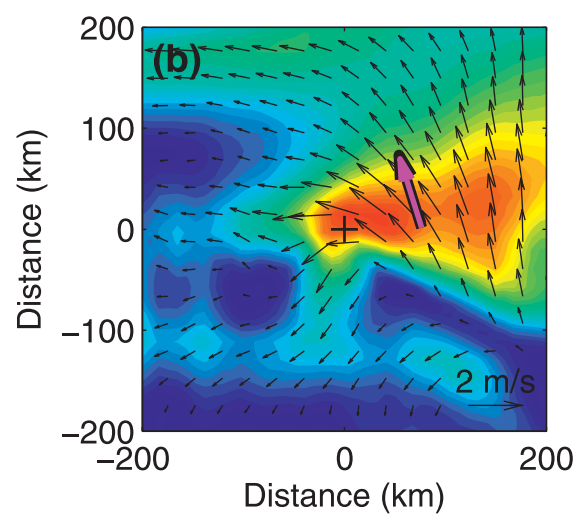

$(\mathrm{m} / \mathrm{s})$

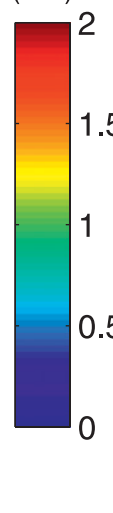

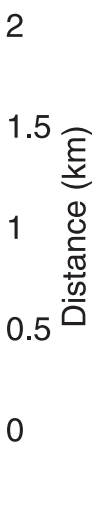

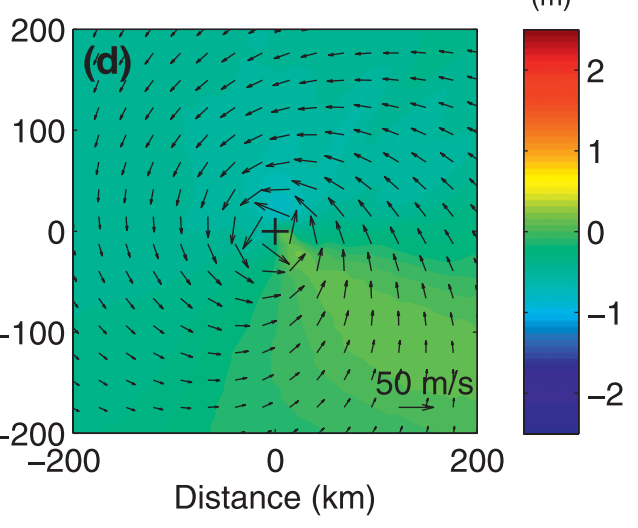

FIG. 11. (a) Significant wave height in color and dominant wavelength and direction in black arrows in experiment C corresponding to the time/location of the SRA measurement on 1800 UTC 9 Sep. (b) Ocean current magnitude (color) and vector (black arrow) at depth of $L /(4 \pi)$. (c) The $H_{s}$ in experiment C minus $H_{s}$ in experiment $\mathrm{D}$. The thin black line shows the 0 contour. (d) The $H_{s}$ in experiment D minus $H_{s}$ in experiment B (color) and wind vector (black arrow). The thick magenta arrow in (a),(b) and (c) shows a pathway of wave packets discussed in the text and the cross denotes the Hurricane Ivan center.

when $C_{g}$, which is typically $\sim 9-10 \mathrm{~m} \mathrm{~s}^{-1}$, is close to $U_{t}$ (near resonance), the reduction of $N$ becomes the largest.

\section{c. Wave spectrum}

Next, we compare individual model spectra obtained at various positions along the 9 September flight track with those of the SRA measurements. Five spectra are selected for the comparisons (white points A-E shown in Fig. 4a). Figure 12 shows the SRA directional wave spectra and the model spectra in all three experiments at locations A-E. All three experiments show good agreement with the observations in simulating the peak wave direction. From Fig. 4a, we can see that locations A-D are in front of the hurricane, and the waves there are actually swells propagated in the tangential direction from the radius of maximum wind at an earlier position of the storm. They were generated because of the resonance, that is, they were exposed to prolonged forcing from wind because the hurricane translation speed was comparable to the group speed of the dominant waves (Moon et al. 2003; Young 2006). We can see that at all five locations, the model produces higher peak energy in experiments $\mathrm{A}$ and $\mathrm{B}$, but similar peak energy to observations in experiment $\mathrm{C}$. Also notice that the angular distribution of the wave energy in experiment $\mathrm{C}$ is widened. The directional spreading tends to become wider when the ocean current is included in the WW3 simulation, being consistent with the Tolman et al. (1996) study of wave interference with the Gulf Stream. This is likely caused by spatial variation of the ocean current, although it is difficult to quantitatively examine the current effect on directional spreading.

At locations A, C, and D, the model produces narrower directional spreading than in the observations in experiments $\mathrm{A}$ and $\mathrm{B}$, but similar directional spreading to observations in experiment C. However, at locations $\mathrm{B}$ and $\mathrm{E}$, the model produces similar directional spreading in experiment $\mathrm{B}$, but larger directional spreading in 


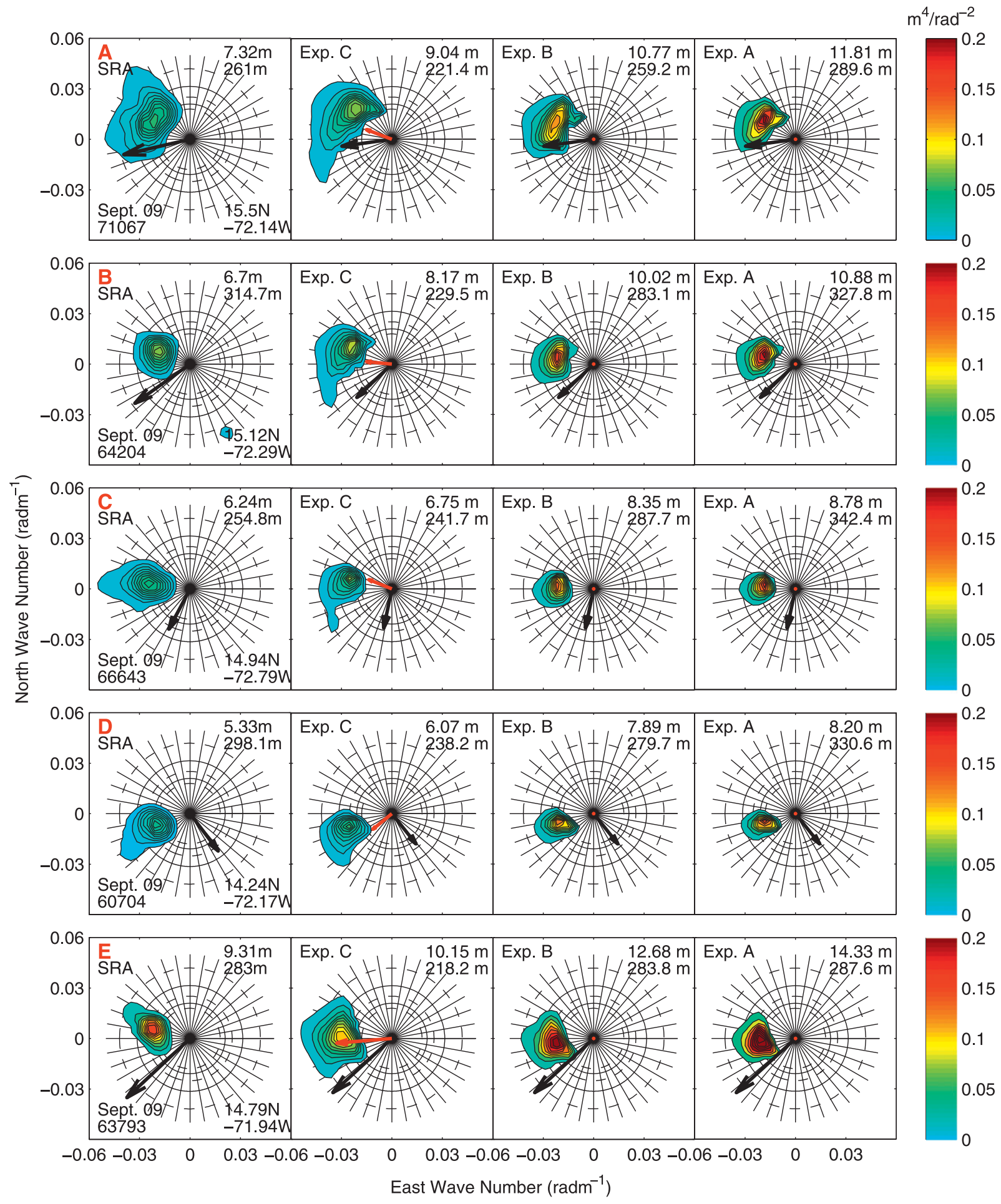

FIG. 12. SRA directional wave spectra and WW3 spectra for experiments A, B, and C at selected locations along the aircraft track indicated in Fig. 4. The dashed circles (outer to inner) correspond to wavelengths of 150, 250, and $350 \mathrm{~m}$. The solid circles indicate wavelengths of 200 and $300 \mathrm{~m}$. The color scales represent spectral density, and each spectrum contains nine contours, linearly spaced from $10 \%$ to $90 \%$ of the peak spectral density. The black arrow and red arrow show wind and current (if available) vectors. They extend in the downstream direction with their length proportional to their magnitude. The wind speed of $30 \mathrm{~m} \mathrm{~s}^{-1}$ corresponds to a length of $0.03 \mathrm{rad}$. The significant wave height and the dominant wavelength are shown in the upper right corner of the SRA and the WW3 spectrum. The location of SRA measurement in latitude and longitude and observation time is shown in the lower right and lower left corners of the SRA spectrum. 

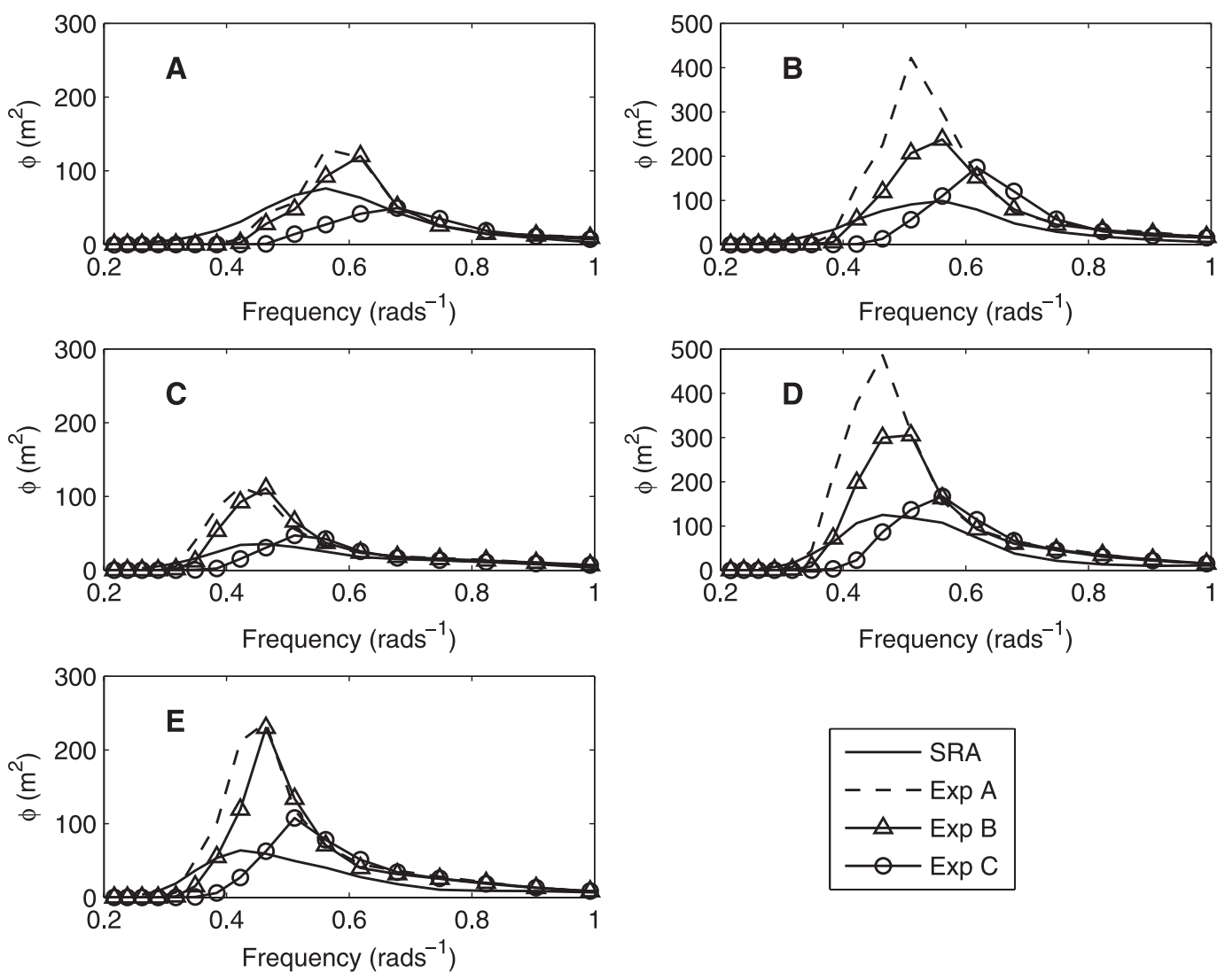

FIG. 13. Comparison of frequency spectrum for different experiments at locations A-E shown in Fig. 4.

experiment $\mathrm{C}$. This discrepancy may be related to some overestimation of the ocean current. In this study, we used the bulk formula for calculating wind stress in POM with the drag coefficient parameterization based on the CWW model. Fan et al. (2009b, manuscript submitted to J. Phys. Oceanogr.) have pointed out that the momentum flux into the ocean can be significantly reduced because of the spatial and temporal variations of the hurricaneinduced surface waves. Fan et al. (2009a) have also shown that the coupled wind-wave-current processes can significantly reduce the momentum flux into the ocean in the right rear quadrant of the hurricane. Since these processes are not considered in our experiments, the momentum flux input to the ocean is likely overestimated. As a result, the currents and current divergence are overestimated too, especially at locations to the right of the hurricane track. Because both B and E are located close to the right of the hurricane track, the overestimation of the directional spreading in the model may be caused by the overestimation of the current. Another possibility is that, as Holthuijsen and Tolman (1991) pointed out, the existence of counter- or following current jet may modify the directional spreading of the wave spectrum. As we have discussed in section 5a, we used the
GDEM monthly climatology to initialize the 3D temperature and current fields in our ocean model. Since the climatology data smooth out most of the mesoscale features, the modeled current field also shows a smooth structure in the Caribbean area and wipes out the effect of mesoscale eddies.

The frequency spectra at locations A-E are shown in Fig. 13. We can see that the frequency spectrums in experiments $\mathrm{A}$ and $\mathrm{B}$ are much higher than the observations at all five locations. When the wave-current interaction is introduced in experiment $\mathrm{C}$, the peak of the frequency spectrum is reduced, which greatly improves the comparison of overall (integrated) energy with observations, although it also consistently shifts the peak toward higher frequency.

\section{d. Effect of loop current on wave prediction}

To investigate the effect of preexisting currents due to mesoscale ocean features on wave prediction, we modified experiment $\mathrm{C}$ such that the Loop Current and its warm-core ring in the Gulf of Mexico are removed from the ocean initialization. Figure $14 \mathrm{c}$ shows an $H_{s}$ comparison between experiment $\mathrm{C}$ results with and without the Loop Current initialization along the 14-15 September 
(a)

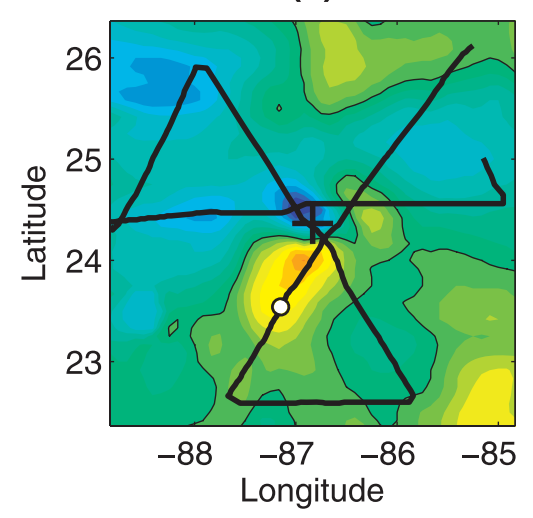

(b)

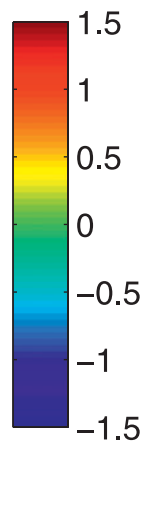

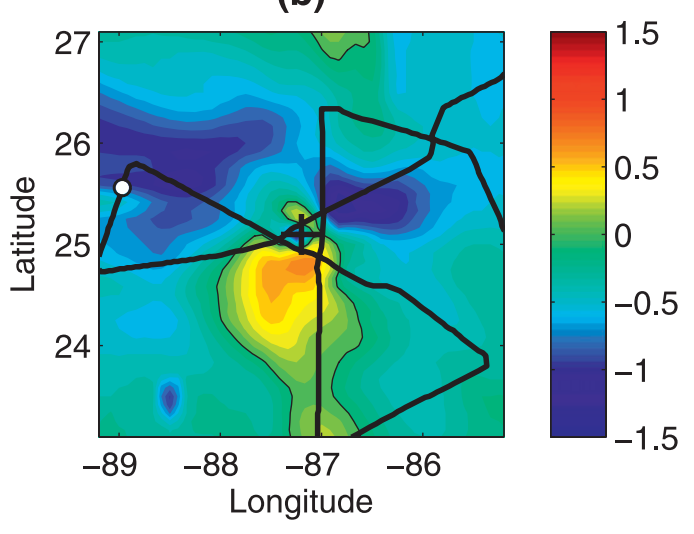

(c)

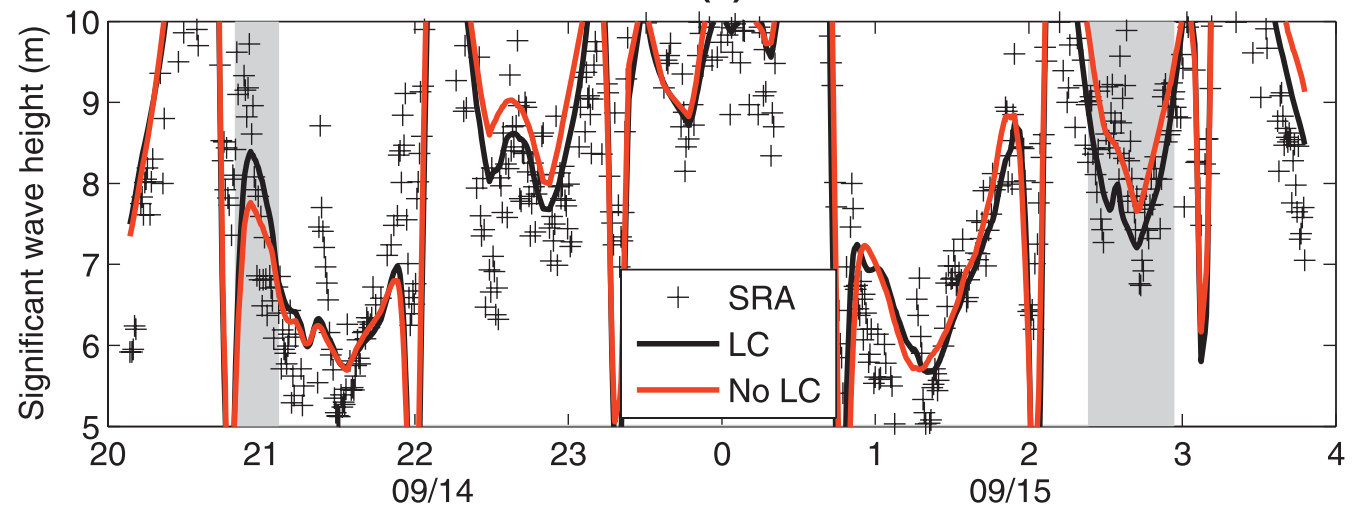

FIG. 14. WW3 $H_{s}$ in experiment $\mathrm{C}$ with Loop Current initialization in the ocean model minus the $H_{s}$ without Loop Current initialization at (a) 2100 UTC 14 Sep and (b) 0240 UTC 15 Sep. In (a) and (b), the thick black line shows the flight track, the thin black line shows the 0 contour, and the white dot shows the location of the flight at the time of the snapshot. (c) The $H_{s}$ with (black line) and without (red line) Loop Current initialization in the ocean model compared with SRA observations (black crosses).

flight. The SRA measurements are also shown for reference. The $H_{s}$ difference between the two experiments is clearly seen along some of the flight sections. Let us examine two such periods highlighted by the gray areas in Fig. 14c.

At 2100 UTC 14 September, $H_{s}$ is significantly larger with the Loop Current initialization. The spatial snapshot of the $H_{s}$ difference with and without the Loop Current initialization is shown at the corresponding time in Fig. 14a. Figure 15c shows the spatial distribution of the ocean temperature at $70-\mathrm{m}$ depth and current field at $L /(4 \pi)$ depth also at the same time. At this time the aircraft is over the edge of the Loop Current (Fig. 15c), where a strong northward current is added due to the LC initialization (Fig. 16a). The wave field at the same time (Fig. 16b) indicates that the dominant waves are propagating southward at this location. If we consider the evolution history of these dominant waves (along the pink arrows in Figs. 16a,b), it is evident that a strong opposing current persisted (i.e., the packet propagation was slower) throughout the wave evolution such that the overall wave spectrum was enhanced. This explains why the predicted $H_{s}$ at this location is increased when the Loop Current initialization is included.

At 0240 UTC 15 September, the predicted $H_{s}$ is significantly smaller with the Loop Current initialization (Fig. 14c). Figure 15d shows that the flight is passing through the southern edge of the warm-core ring at this time. Because of the initialization of the warm-core ring, a strong westward current is added at that location (Fig. 16c). The wave field at the same time (Fig. 16d) shows that the dominant waves are propagating westward. Again, the evolution history of these dominant waves (along the pink arrows in Figs. 16c,d) is such that a strong positive (aligned) current accelerated the wave packet propagation and reduced the spectral level throughout the wave evolution.

These two examples clearly demonstrate that strong currents due to preexisting mesoscale ocean features may 


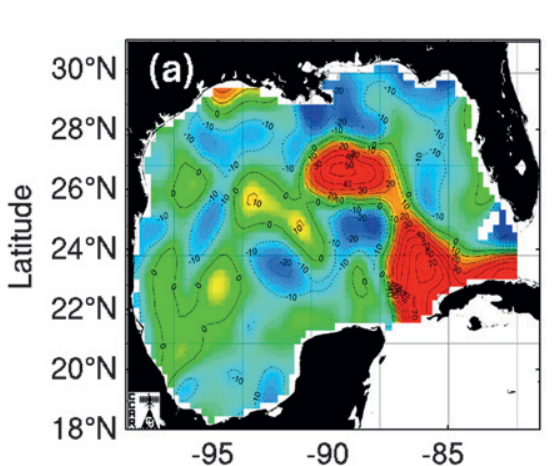

(a)

Longitude

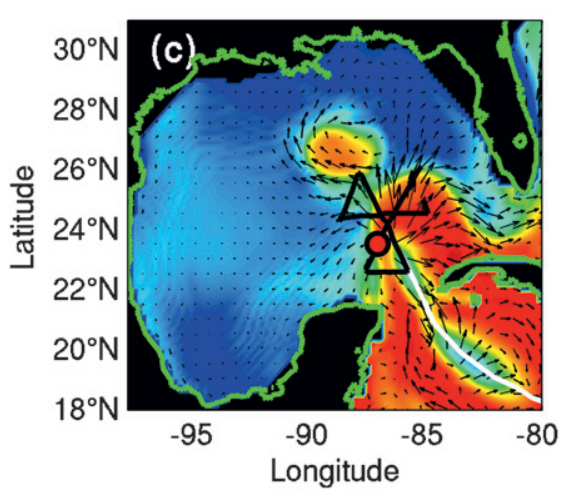

$(\mathrm{cm})$

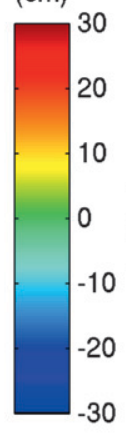

$\left({ }^{\circ} \mathrm{C}\right)$

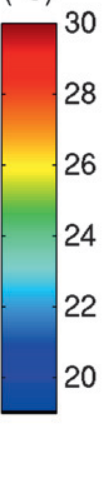

$\left({ }^{\circ} \mathrm{C}\right)$

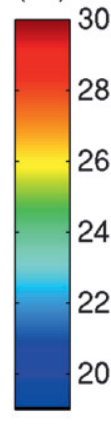

$-90$

Longitude

$\left({ }^{\circ} \mathrm{C}\right)$

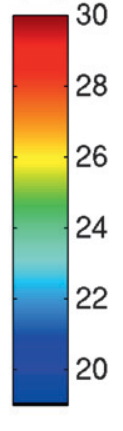

FIG. 15. (a) Satellite altimetry map in the Gulf of Mexico on 12 Sep 2004, and ocean temperature at 70-m depth with current vectors at $L /(4 \pi)$ depth in the ocean model at (b) 1200 UTC 12 Sep, (c) 2100 UTC 14 Sep, and (d) 0240 UTC $15 \mathrm{Sep}$. In (c) and (d), the black line is flight track, the white line is hurricane track, and the red dot shows the location of the flight at this time.

significantly modify the wave field prediction mainly because such currents accelerate or decelerate the wave propagation.

\section{Summary and conclusions}

It has been shown in previous studies that the operational wave model WW3 overestimates the significant wave height under very high wind conditions, such as under strong hurricanes. In this study we have investigated how the performance of WW3 is affected by different drag coefficient parameterizations and by including the effect of wave-current interaction. Hurricane Ivan in 2004 has been used as a test case since several observations were available for comparison, including the detailed direct observations of wave spectra from the NASA Scanning Radar Altimeter, NDBC buoy, and satellite measurements.

The drag coefficient has been parameterized by either using the original formulation in WAVEWATCH III or the coupled wave-wind model, which is based on the explicit integration of the waveform drag. The effect of wave-current interaction has been included by passing the hurricane-induced currents calculated by the Princeton Ocean Model into the coupled wave-wind model. The real-time wind analysis during Hurricane Ivan produced by the NOAA/Hurricane Research Division has been used to force both the wave model and the ocean model.

The results can be summarized as follows:

1) All experiments in this study show good prediction of wave direction, indicating that the effects of the wind stress parameterization and wave-current interaction on wave direction prediction are negligible.

2) The original WAVEWATCH III drag parameterization tends to overestimate the significant wave height, wave energy, and the dominant wavelength under very strong wind forcing, and the error seems to increase as the significant wave height increases.

3) The improved stress parameterization, together with the wave-current interaction, is shown to improve forecasts of significant wave height and wave energy.

4) The hurricane-induced ocean current tends to reduce the significant wave height mainly because it 
(a)

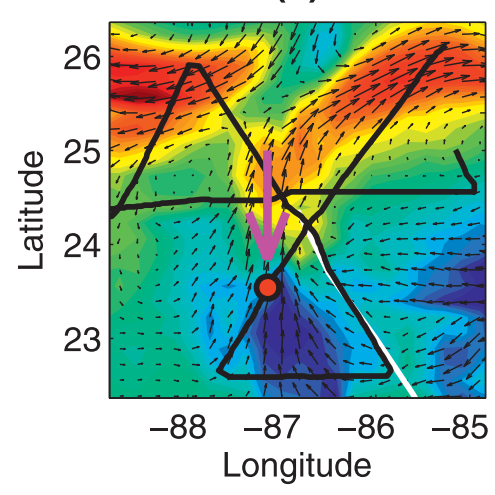

(b)

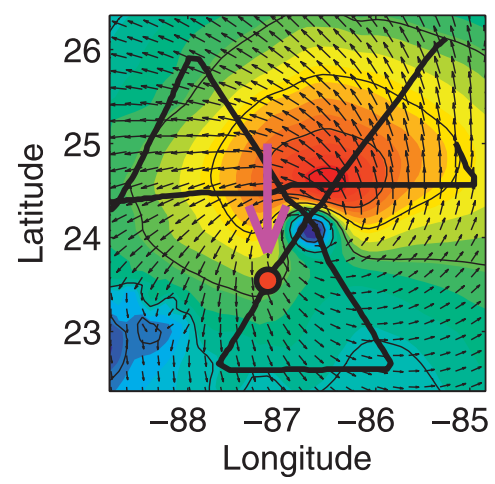

$(\mathrm{m} / \mathrm{s})$

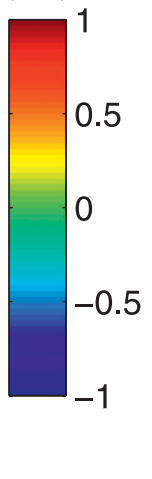

(m)

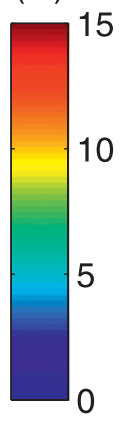

(c)

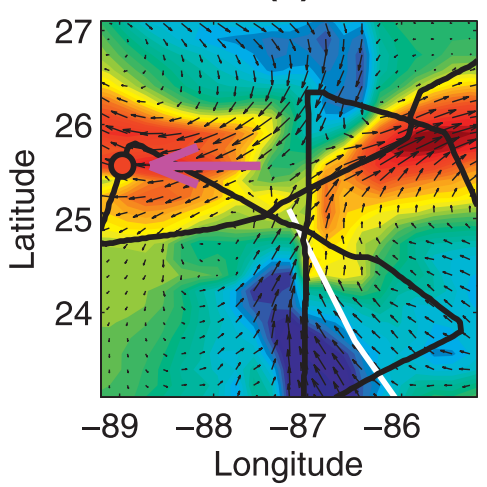

(d)

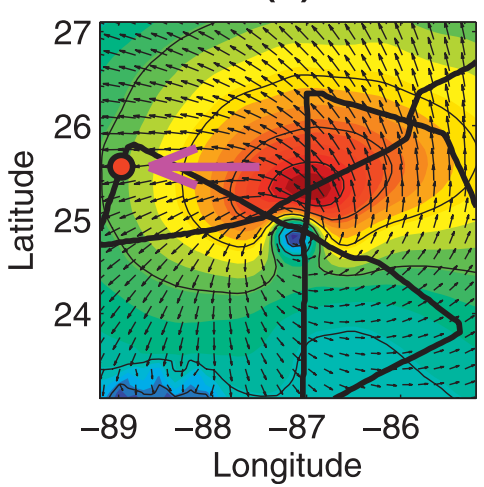

$(\mathrm{m} / \mathrm{s})$

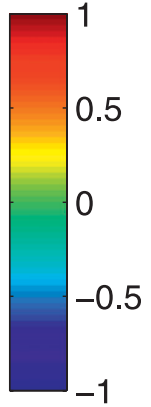

(m)

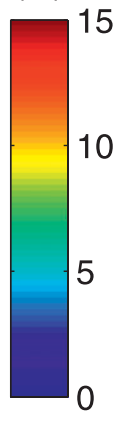

FIG. 16. (a) Ocean current difference between the experiments with and without the Loop Current initialization at 2100 UTC 14 Sep. (b) Significant wave height in color and dominant wavelength and direction in black arrows at 2100 UTC 14 Sep. (c) Ocean current difference between the experiments with and without the Loop Current initialization at 0240 UTC 15 Sep. (d) Significant wave height in color and dominant wavelength and direction in black arrows at 0240 UTC 15 Sep. The black line shows the flight track and the red dots show the location of the flight at the time that the current and wave field are shown. The pink arrow shows the wave propagation path.

increases the advection velocity of the wave packet. Spatial variation of the current widens the directional spreading of the wave spectrum.

5) When the hurricane moves over a preexisting mesoscale ocean feature, such as the Loop Current in the Gulf of Mexico or a warm- and cold-core ring, the wave field may be significantly modified. This is mainly because strong currents associated with these features accelerate or decelerate the wave propagation and thus cause the modulation of the wave spectrum.

The results presented in this paper confirm that a fully coupled wind-wave-ocean system as suggested in Fan et al. (2009a) is necessary to accurately forecast wave fields in hurricanes.

Acknowledgments. The authors wish to thank Dr. Hendrik Tolman for providing the latest version of NOAA's WAVEWATCH III model and valuable comments. Remko Scharroo (altimetrics.com) is thanked for collecting and organizing data from radar altimeters carried by five different satellites passing through the Hurricane Ivan geographic area during its lifetime. He supplied over 80 files of data along with annotated geographic maps of color-coded wind speed and wave height along the satellite tracks that made it much easier to identify the closest approach to Hurricane Ivan (Figs. 1, 9). We also thank NOAA/AOML/Hurricane Research Division for providing the wind analysis (HWIND). This research was funded by NOAA Grant NOAA4400080656 and Korea Ocean Research and Development Institute (KORDI) Grant 0001377 awarded to the Graduate School of Oceanography at URI, and WeatherPredict Consulting Inc. via a grant to the URI Foundation. Support for E. J. Walsh and the acquisition and analysis of the SRA data were provided by the NASA Physical Oceanography program and the ONR CBLAST program. 


\section{REFERENCES}

Bender, M. A., I. Ginis, R. Tuleya, B. Thomas, and T. Marchok, 2007: The operational GFDL coupled hurricane-ocean prediction system and summary of its performance. Mon. Wea. Rev., 135, 3965-3989.

Black, P. G., and Coauthors, 2007: Air-sea exchange in hurricanes: Synthesis of observations from the coupled boundary layer airsea transfer experiment. Bull. Amer. Meteor. Soc., 88, 357-374.

Blumberg, A. F., and G. L. Mellor, 1987: A description of a threedimensional coastal ocean circulation model. Three-Dimensional Coastal Ocean Models, N. S. Heaps, Ed., Amer. Geophys. Union, 1-16.

Chao, Y. Y., J.-H. G. M. Alves, and H. L. Tolman, 2005: An operational system for predicting hurricane-generated wind waves in the north Atlantic Ocean. Wea. Forecasting, 20, 652-671.

Donelan, M. A., B. K. Haus, N. Reul, W. J. Plant, M. Stiassnie, H. C. Graber, O. B. Brown, and E. S. Saltzman, 2004: On the limiting aerodynamic roughness of the ocean in very strong winds. Geophys. Res. Lett., 31, L18306, doi:10.1029/ 2004GL019460.

Falkovich, A., I. Ginis, and S. Lord, 2005: Ocean data assimilation and initialization procedure for the coupled GFDL/URI hurricane prediction system. J. Atmos. Oceanic Technol., 22, 1918-1932.

Fan, Y., I. Ginis, and T. Hara, 2009a: The effect of wind-wavecurrent interaction on air-sea momentum fluxes and ocean response in tropical cyclones. J. Phys. Oceanogr., 39, 10191034.

Funakoshi, Y., S. C. Hagen, and P. Bacopoulis, 2008: Coupling of hydrodynamic and wave models: Case study for Hurricane Floyd (1999) hindcast. J. Waterway, Port, Coastal, Ocean Eng., 134, 321-335.

Ginis, I., 2002: Tropical cyclone-ocean interactions. AtmosphereOcean Interactions, W. Perrie, Ed., Advances in Fluid Mechanics Series, Vol. 33, WIT Press, 83-114.

Hara, T., and S. E. Belcher, 2002: Wind forcing in the equilibrium range of wind-wave spectra. J. Fluid Mech., 470, 223-245.

—, and —, 2004: Wind profile and drag coefficient over mature ocean surface wave spectra. J. Phys. Oceanogr., 34, 2345-2358.

Holthuijsen, L. H., and H. Tolman, 1991: Effects of the Gulf Stream on ocean waves. J. Geophys., 96, 12 755-12 771.

Moon, I.-J., I. Ginis, T. Hara, H. Tolman, C. W. Wright, and E. J. Walsh, 2003: Numerical simulation of sea-surface directional wave spectra under hurricane wind forcing. J. Phys. Oceanogr., 33, 1680-1706.

,,,--- and,$- 2004 \mathrm{a}$ : Effect of surface waves on airsea momentum exchange. Part I: Effect of mature and growing seas. J. Atmos. Sci., 61, 2321-2333.

$\longrightarrow, \ldots$, and $\_$, 2004b: Effect of surface waves on air-sea momentum exchange. Part II: Behavior of drag coefficient under tropical cyclones. J. Atmos. Sci., 61, 2334-2347.

,$- \ldots$, and — 2008: Impact of reduced drag coefficient on ocean wave modeling under hurricane conditions. Mon. Wea. Rev., 136, 1217-1223.

Powell, M. D., 1980: Evaluations of diagnostic marine boundary-layer models applied to hurricanes. Mon. Wea. Rev., 108, 757-766.

—, S. H. Houston, and T. A. Reinhold, 1996: Hurricane Andrew's landfall in south Florida. Part I: Standardizing measurements for documentation of surface wind fields. Wea. Forecasting, 11, 304-328.
,-- L. R. Amat, and N. Morisseau-Leroy, 1998: The HRD real-time hurricane wind analysis system. J. Wind Eng. Ind. Aerodyn., 77-78, 53-64.

— , P. J. Vickery, and T. A. Reinhold, 2003: Reduced drag coefficient for high wind speeds in tropical cyclones. Nature, $\mathbf{4 2 2}$, 279-283.

Shay, L. K., G. J. Goni, and P. G. Black, 2000: Effects of a warm oceanic feature on Hurricane Opal. Mon. Wea. Rev., 128, 1366-1383.

Teague, W. J., M. J. Carron, and P. J. Hogan, 1990: A comparison between the Generalized Digital Environmental Model and Levitus climatologies. J. Geophys. Res., 95, 7167-7183.

Tolman, H. L., 1998: Validation of a new global wave forecast system at NCEP. Ocean Wave Measurements and Analysis, B. L. Edge and J. M. Helmsley, Eds., ASCE, 777-786.

- 2002: Validation of WAVEWATCH III version 1.15 for a global domain. NOAA/NWS/NCEP/OMB Tech. Note 213, $33 \mathrm{pp}$.

_ 2004: Inverse modeling of discrete interaction approximations for nonlinear interactions in wind waves. Ocean Modell., 6, 405-422.

—_, and J.-H. G. M. Alves, 2005: Numerical modeling of wind waves generated by tropical cyclones using moving grids. Ocean Modell., 9, 305-323.

_, S. H. Hasselmann, H. Graber, R. E. Jensen, and L. Cavaleri, 1996: Applications to wave hindcasting and forecasting: Application to the open ocean. Dynamics and Modelling of Ocean Waves, G. J. Komen et al., Eds., Cambridge University Press, 355-359.

—, B. Balasubramaniyan, L. D. Burroughs, D. Chalikov, Y. Y. Chao, H. S. Chen, and V. M. Gerald, 2002: Development and implementation of wind generated ocean surface wave models at NCEP. Wea. Forecasting, 17, 311-333.

— J. H. G. M. Alves, and Y. Y. Chao, 2005: Operational forecasting of wind-generated waves by Hurricane Isabel at NCEP. Wea. Forecasting, 20, 544-557.

Vledder, G., T. Herbers, R. Jensen, D. Resio, and B. Tracy, 2001: Modelling of non-linear quadruplet wave-wave interactions in operational wave models. Coastal Engineering (Conference Proceedings, Sydney, Australia), B. L. Edge, Ed., ASCE, 797-811.

Walsh, E. J., and Coauthors, 2002: Hurricane directional wave spectrum spatial variation at landfall. J. Phys. Oceanogr., 32, 1667-1684.

Wang, D. W., D. A. Mitchell, W. J. Teague, E. Jarosz, and M. S. Hulbert, 2005: Extreme waves under Hurricane Ivan. Science, 309 (5736), 896.

Wingeart, K. M., W. C. O'Reilly, T. H. C. Herbers, P. A. Wittmann, R. E. Jenssen, and H. L. Tolman, 2001: Validation of operational global wave prediction models with spectral buoy data. Ocean Wave Measurement and Analysis, B. L. Edge and J. M. Hemsley, Eds., ASCE, 590-599.

Wright, C. W., and Coauthors, 2001: Hurricane directional wave spectrum spatial variation in the open ocean. J. Phys. Oceanogr., 31, 2472-2488.

Yablonsky, R. M., and I. Ginis, 2008: Improving the ocean initialization of coupled hurricane-ocean models using featurebased data assimilation. Mon. Wea. Rev., 136, 2592-2607.

Young, I. R., 2006: Directional spectra of hurricane wind-waves. J. Geophys. Res., 111, C08020, doi:10.1029/2006JC003540. 